\title{
Screen-printed electrodes modified with green-synthesized gold nanoparticles for the electrochemical determination of aminothiols
}

Valeree Ross R. Bernardo-Boongaling ${ }^{1,3}$, Núria Serrano ${ }^{1}$, Juan José García-Guzmán ${ }^{3}$, José María Palacios-Santander ${ }^{3}$, José Manuel Díaz-Cruz ${ }^{1,2}$.

1 Department of Chemical Engineering and Analytical Chemistry, University of Barcelona, Martí i Franquès 1-11, 08028-Barcelona, Spain.

2 Institut de Recerca de l'Aigua (IdRA), University of Barcelona.

3 Institute of Research on Electron Microscopy and Materials (IMEYMAT), Department of Analytical Chemistry, Faculty of Sciences, Campus de Excelencia Internacional del Mar (CEIMAR), University of Cadiz, Campus Universitario de Puerto Real, Polígono del Río San Pedro S/N, 11510, Puerto Real, Cádiz, Spain

* Corresponding author. Phone: (34) 9340217 96, e-mail: josemanuel.diaz@ub.edu

\begin{abstract}
Commercially available gold screen-printed electrodes cured at high temperature were modified or functionalized at the surface with gold nanoparticles, mainly produced by a green synthesis method, and other carbon-based nanomaterials in order to enhance the electron transfer between the sulfhydryl groups of the aminothiols cysteine (Cys), methionine (Met), glutathione (GSH) and homocysteine (hCys) and the electrode. The electrochemical characterization by cyclic and differential pulse voltammetry of some of the modified electrodes showed an improved performance in terms of sensitivity, reproducibility, repeatability, linearity range and limits of detection $\left(12,1,0.2\right.$ and $1 \mu \mathrm{mol} \mathrm{L}{ }^{-1}$ for Cys, Met, GSH, hCys, respectively) and quantification (40, 2, 0.5 and $2 \mu \mathrm{mol} \mathrm{L}^{-1}$ for Cys, Met, GSH, hCys, respectively) as compared to unmodified units. Then, some of these modified devices were successfully applied to the determination of cysteine and methionine in dietary supplements by means of liquid chromatography with amperometric detection.
\end{abstract}

Keywords: Voltammetry, screen-printed electrodes, gold nanoparticles, carbon nanotubes, carbon nanofibers, aminothiols, liquid chromatography, amperometric detection. 


\section{Introduction}

Human bodies are continuously exposed to oxidative stress. Therefore, they require the presence of antioxidant substances to counteract free radicals and to maintain a reduced state regardless of the body's environment [1]. For this purpose, aminothiols are especially adequate $[2,3]$. The antioxidant power of aminothiols arises from their oxidation to disulfide:

$$
2 \mathrm{R}-\mathrm{SH} \rightarrow \mathrm{R}-\mathrm{S}-\mathrm{S}-\mathrm{R}+2 \mathrm{e}^{-}+2 \mathrm{H}^{+}
$$

The structures of the aminothiols considered in this study are shown in Figure 1. The metabolic pathways of aminothiols are strongly linked. Homocysteine is a critical regulatory intermediate of methionine cycle, acting as a precursor for cysteine in the transulfuration pathway and for methionine synthesis via re-methylation. Increased levels of cysteine and homocysteine are associated with cardiovascular diseases while low levels of glutathione independently predict impaired coronary microvascular function in patients with coronary artherosclerotic heart disease [4]. Decreased glutathione levels have also been associated with diabetes, alcoholic liver disease, AIDS, cataracts, carcinogenesis and aging while altered levels of homocysteine have been associated with folate and vitamin $B_{12}$ deficiency, homocystinuria and cardiovascular disease [5].

Methionine is an essential sulphur-containing amino acid that is part of the synthesis of epinephrine, choline and creatinine. Its deficiency leads to metabolic disorders, toxaemia, muscle paralysis, depression and impaired growth [6]. Methionine-deficient diets also result in elevated blood spermidine; thus, methionine supplements are given to lower blood histamine by increasing its breakdown. Methionine produces the non-essential amino acid cysteine which has an important role in protein cross-linking and is used in some antibiotics for skindamage treatments and as a radioprotective agent. Aside from this, it is used in the food industry as antioxidant, in the pharmaceutical industry as biomarker and in drugs formulation [7]. Cysteine's sulfhydryl group is responsible for the disulfide bridges in peptides and proteins and is involved in various cellular functions such as protein synthesis, metabolism and detoxification [8]. Cysteine is important in energy metabolism and it is a precursor of glutathione. Glutathione is an antioxidant that binds with toxic chemicals in the liver and is also important in red and white blood cell formation. As a tripeptide involved in several biological processes, the determination of glutathione levels in blood can help clinical diagnosis at the early stages of the disease. Aside from being an antioxidant, it also suppresses skin hyperpigmentation [9]. Having a slightly higher pKa than glutathione, homocysteine is 
known to be a risk factor for cardiovascular disease and stroke in humans. Homocysteine editing by tRNA synthetases produces homocysteine thiolactone which acylates irreversibly the lysine side chains of protein and causes protein damage and autoimmune responses. Homocysteine metabolism is relevant to the understanding of psychosis, arteriosclerosis and is used as the biochemical basis of all nutrient therapies. There are no supplements of homocysteine available since raise in the plasma levels of homocysteine is more detrimental than beneficiary.

Cysteine, methionine and glutathione are often taken as dietary supplements for the purposes mentioned previously as they aid in metabolic an immunity functions. However, previous studies by Grimble [10] have shown that high dietary intakes of methionine raise the homocysteine levels causing alterations in the immune functions. Moreover, it is important to note that sulphur-containing amino acids are mild chelators and can thus bind with metals in human body and may remove some vital minerals along with the toxic ones. For this reasons, it is useful to check and verify the correct dose or concentration of these amino acids when taken as supplements.

The facts described so far evidence the importance of an accurate monitoring of the levels of aminothiols in plasma and in dietary supplements. Among the different techniques available for that, liquid chromatography with UV-vis or fluorescence detection is especially appropriate, but it requires derivatisation of thiol groups $[11,12]$. As for electrochemical methods, they take advantage of the electroactive character of thiol groups to develop simple, rapid, low-cost and easily automated screening assays without need of derivatisation [13, 14]. However, a setback arises due to the dependency of the electrochemical behaviour of these aminothiols on the thiol group that makes their signals very similar to each other [15]. This lack of selectivity can be counterbalanced by combining a separation technique, typically liquid chromatography (LC), with amperometric detection [16-19] or by using arrays of electrodes with different selectivities (cross response) combined into electronic tongues [15, 20-22]. Another problem in the electrochemical detection of aminothiols is the slow kinetics of oxidation which decreases sensitivity and requires too positive working potentials, susceptible to many interferences [23]. To solve this problem out, the use of nanoparticles (NP) appears as a promising strategy, since the resulting increase in the specific area of the electrode and the catalytic properties of many nanomaterials should improve the electrochemical oxidation rate and, hence, the sensitivity of the electrochemical measurements [24-27]. 
In recent years, screen-printed electrodes (SPE) have emerged as a simple, disposable, nontoxic and low-cost alternative to mercury-based and conventional solid electrodes for the voltammetric determination of many substances [28-30]. Moreover, they have shown to be a convenient substrate to be modified with nanoparticles [31, 32].

Nanosized particles of noble metals, especially gold nanoparticles (AuNPs) and silver nanoparticles (AgNPs), have received great interest due to their attractive electrical, optical and thermal properties aside from its catalytic properties and applications in several fields. Metal nanoparticles are synthesized electrochemically, by radiation, thermal decomposition, vapour deposition, reduction in micro-emulsion, and by means of green or ecological technology [33-36]. The nanostructure platform which has relative high surface area-tovolume ratio, seems to show excellent sensitivity and low experimental detection limit [37-39]. Metal nanoparticles have excellent conductivity and catalytic properties that enhance the electron transfer between redox centres in proteins and electrode surfaces. In general terms, AuNPs are easier to obtain with homogeneous size distribution and easier to functionalise with thiol groups, whereas silver AgNPs are considerably cheaper and present higher electrical conductivity and catalytic activity [24, 27]. Bimetallic gold/silver nanostructures [27] and combinations of AuNPs and AgNPs with carbon-based nanomaterials [40,41] have also interesting properties. Recently, AuNPs and AgNPs have been incorporated to screen-printed electrodes with excellent results $[42,43]$. It has been reported that AuNPs can immobilize proteins through the formation of covalent bonds between gold atoms and the amine groups and cysteine residues of proteins [44]. Several electrochemical applications of AuNPs have been investigated including AuNPs -based electrochemical sensors, bio-electrochemical sensors, genosensors and immunosensors. The synthesis of these AuNPs is often tedious because of its high surface energy that makes them extremely reactive which causes aggregation without protection from biomolecules, green agents, polymers and dendrimers [37].

Commercial screen-printed gold electrodes (SPAUE) have been applied to the amperometric detection of aminothiols in flow injection analysis (FIA) and liquid chromatography (LC) in works like that by Garcia-Gonzalez et al. [45] or Cavanillas et al. [16]. However, sensitivity was not especially good due to the slow oxidation kinetics of thiol groups at the bare gold surface. The use of carbon nanomaterials instead of bare gold showed an improved performance of the amperometric detection of thiols [46]. Nevertheless, modification of SPAuE with electrodeposited AuNPs also appears to be a good alternative to improve their performance as 
it happens in the work by Wan et al. [42], were the modified devices are successfully applied to the determination of lead and copper by voltammetry.

In the present work, we intend to verify if the good features of AuNPs modification shown in the analysis of heavy metals can be extended to the determination of aminothiols. For this purpose, commercial SPAuE have been modified or functionalized with AuNPs, mainly synthesized using a fast and green procedure based on sonocatalysis, recently developed by Cubillana-Aguilera et al. [33, 34] and other nanocarbon materials. The surface modification has been verified by different characterization techniques, such as scanning and transmission electron microscopy, electron diffraction and energy dispersive X-ray spectroscopy. Afterwards, the electrodes have been also electrochemically characterized. Finally, the most promising modifications have been applied to the determination of cysteine and methionine in dietary supplements by FIA and LC using amperometric detection.

\section{Experimental}

\subsection{Reagents}

All reagents employed, unless otherwise indicated, were of analytical grade. L-methionine, glutathione, potassium nitrate, potassium dihydrogen phosphate and sulfuric acid were purchased from Merck (Darmstadt, Germany); L-cysteine, DL-homocysteine, potassium hexacyanoferrate (II) trihydrate, potassium hydrogen phosphate, sodium hydrogen phosphate, potassium gold (III) chloride, carbon nanotubes (ref. MKBF8277V) and trifluoroacetic acid were obtained from Sigma-Aldrich (Steinheim, Germany); sodium dihydrogen phosphate and sodium citrate dihydrate were purchased from Scharlab (Barcelona, Spain); methanol was obtained from Thermo Fisher Scientific (Waltham, USA); and $\mathrm{COOH}$-functionalized multiwalled carbon nanotubes were purchased from Dropsens (Oviedo, Spain). Nutritional supplements of L-cysteine and L-methionine were purchased in local markets and diluted up to 40 and $10 \mu \mathrm{mol} \cdot \mathrm{L}^{-1}$ taking into account the concentration provided by the manufacturer. All solutions were prepared in purified water obtained from an Elix 3 coupled to a Milli-Q system by Millipore (Bedford, MA, USA).

\subsection{Instrumentation}

Voltammetric measurements were performed with a potentiostat Autolab PGSTAT20 by EcoChemie (Utrecht, The Netherlands) connected to a 663 VA stand module by Metrohm (Herisau, Switzerland) and a personal computer to control the measurements by means of the 
GPES program (version 4.9). Gold screen-printed electrodes (SPAuE) cured at high temperature (reference DRP-220AT) and carbon nanofibers screen-printed electrodes (SPCNFE, reference DRP-110CNF) were purchased from Dropsens (Oviedo, Spain) and attached to the VA Stand by means of a flexible cable (reference CAC) by Dropsens. In order to improve the accuracy of the measurements, an external $\mathrm{Ag} / \mathrm{AgCl}$ reference electrode and an external platinum auxiliary electrode (both by Metrohm) were used in some cases.

pH measurements were done using a MicropH2000 pH-meter by Crison (Barcelona, Spain). Solutions were mixed using Color Squid by IKA Works (Staufen, Germany). An ultrasonic bath 2510 by Branson Ultrasonics (Danbury, Connecticut, USA) was used to remove oxygen from the solutions.

AuNPs were synthesized using a SONICATOR 3000 from Misonix (Farming Dale, NY USA) equipped with a $13-\mathrm{mm}$ titanium tip. The instrument operates at $20 \mathrm{kHz}$, providing a maximum output power density of $122.2 \mathrm{Wcm}^{-2}$ and a maximum output power of $600 \mathrm{~W}$.

UV measurements were made by using a V-550 UV Visible spectrophotometer by Jasco (Easton, Maryland, USA) controlled with a personal computer through Jasco 32 software.

Scanning electron microscope FEI Nova NANOSEM 450 and transmission electron microscope Talos F200X TEM (Thermo Fisher Scientific - FEI, Hillsboro, USA) equipments were employed in order to obtain information about the presence and distribution of AuNPs onto the SPAuE electrodes surface, and to give evidences about the presence of AuNPs onto the surface of MWCNTs, and hence of the modification of the SPAuE surface with the MWCNTs/AuNPs nanocomposite. Low voltage $(3 \mathrm{kV})$ and two different detectors (secondary electrons and backscattered electrons detector) were employed for SEM. TEM micrographs were taken at $200 \mathrm{kV}$ using either the scanning/transmission (STEM) mode with a high-angle annular darkfield (HAADF) detector and the high resolution mode (HREM). Energy dispersive X-ray spectroscopy (EDS) for microanalysis coupled to SEM, and chemical characterization with compositional mapping and electron diffraction in TEM were also performed.

A Microtrac Nanotrac Wave particle analyser (Meerbusch, Germany) was used to obtain particle size distribution of synthesized AuNPs. The instrument is based on the dynamic light scattering (DLS) technique and it is equipped with a laser diode emitting at a wavelength of $780 \mathrm{~nm}$, with a nominal power of $3 \mathrm{~mW}$.

A Minipuls 3 peristaltic pump by Gilson (Middleton, WI, USA) was used for flow injection analysis (FIA) measurements. Liquid chromatography analyses with electrochemical detection 
(LC-EC) were performed using a 1200 series chromatographic system by Agilent Technologies (Santa Clara, California, USA) with an auto injector module, a quaternary pump, a vacuum degasser and a personal computer with the Agilent ChemStation software for instrument control and for data processing. An isocratic chromatographic separation at room temperature was achieved by reversed-phase mode with a $5 \mu \mathrm{m}, 25 \mathrm{~cm} \times 4.6 \mathrm{~mm}$ Ascentis C18 column supplied by Supelco (Bellefonte, PA, USA) fitted with an Agilent Eclipse XDB-C8 guard column (4.6 $\mathrm{mm} \times 12.5 \mathrm{~mm}, 5 \mu \mathrm{m}$ ). The electrochemical detector was a $\mu$-AUTOLAB Type III by Metrom (Herisau, Switzerland) with data acquisition through GPES software. For both FIA and LC-EC measurements, the flow cell HPLCELL by Dropsens (Oviedo, Spain) adapted to screenprinted devices was employed.

\subsection{Procedures}

\subsubsection{Conditioning of screen-printed electrodes}

In order to ensure good reproducibility, the fouling of the electroactive surface of the gold electrode caused by the adsorption of thiols was prevented by means of a pre-treatment of SPAuE units [16]. For this purpose, four different strategies were applied, which combined in different ways a pre-treatment consisting of 30 fast scans from 1.4 to $-0.9 \mathrm{~V}$ at $1.0 \mathrm{~V} / \mathrm{s}$ and 2 slow scans from 1.3 to $-0.9 \mathrm{~V}$ at $0.1 \mathrm{~V} / \mathrm{s}$ and a second electrochemical treatment consisting of the application of a conditioning potential of $-1.0 \mathrm{~V}$ during $30 \mathrm{~s}$. The four procedures were as follows: no pre-treatment (A), pre-treatment at every run (B), pre-treatment and second electrochemical treatment before every run $(C)$ and pre-treatment every run but second electrochemical treatment only in the initial run (D).

\subsubsection{Synthesis of gold nanoparticles}

AuNPs were prepared via ultrasonication with a high energy ultrasound probe. The tip probe was cleaned for 2 min using ethanol at an amplitude of $40 \%$ (approx. $0.7 \mathrm{~W} \mathrm{~cm}^{-2}$ ), then set to an amplitude of $13 \%\left(4.9 \mathrm{~W} \mathrm{~cm}^{-2}\right)$. Citrate $\left(0.250 \mathrm{~mL}\right.$ of a $38.8 \mathrm{mmol} \mathrm{L}^{-1}$ solution) was added to $\mathrm{KAuCL}_{4}\left(1.25 \mathrm{~mL}\right.$ of a $1.5 \mathrm{mmol} \mathrm{L}^{-1}$ solution) after $2 \mathrm{~min}$. Ultrasonication was stopped at $5 \mathrm{~min}$ and $50 \mathrm{~s}$, when a red wine colloidal solution containing AuNPs was obtained.

\subsubsection{Characterisation of gold nanoparticles}

UV-Visible spectra of AuNPs colloids from 400 to $800 \mathrm{~nm}$ were registered to verify the success of the synthesis and DLS technique was used to obtain the particle size distribution. In these measurements, ultrapure water was employed as blank. 


\subsubsection{Electrode modifications}

The procedures for the different electrode modifications tested are summarized in Table 1. Briefly, two different electrode materials were used: screen-printed gold or carbon nanofiber electrodes, pre-treated or not. Immobilisation of AuNPs on the electrode surface was performed by drop-casting, electrodeposition or both; carbon nanotubes were also deposited by drop-casting, either alone or mixed with AuNPs, and in some cases $\mathrm{Nafion}^{\circledR}$, polyaniline nanofibers studded with AuNPs, glutaraldehyde or even other solvents were utilized to avoid leaching from the electrode surface. At the end, 16 different electrode configurations were assayed. For more details, see Table 1.

\subsubsection{Voltammetric calibration with aminothiols}

$50 \mu \mathrm{L}$ of a $10 \mathrm{mmol} \mathrm{L}^{-1}$ solution of aminothiol was added to $10 \mathrm{~mL}$ of $0.10 \mathrm{~mol} \mathrm{~L}^{-1}$ phosphate buffer solution (PBS) of $\mathrm{pH}$ 7.0. The resulting solution was deaerated with $\mathrm{N}_{2}$ gas for $30 \mathrm{~s}$. Increments of $50 \mu \mathrm{L}$ were added and 3 cyclic voltammetry (CV) scans were performed after every addition.

\subsubsection{LC measurements}

Isocratic elution was made with a proportion $98: 2(\mathrm{v} / \mathrm{v})$ of i) a $0.05 \%(\mathrm{v} / \mathrm{v})$ solution of trifluoroacetic acid (TFA) in ultrapure water and ii) methanol. An injection volume of $10 \mu \mathrm{L}$ was used. Separation was achieved at room temperature $\left(20^{\circ} \mathrm{C}\right)$.

\section{Results and discussion}

\subsection{Characterisation of the bare gold electrodes by cyclic voltammetry}

Experiments using bare SPAuE cured at high temperature were done to determine its electrochemical behaviour. The cyclic voltammograms obtained in the presence of a model solution containing $5.0 \mathrm{mmol} \mathrm{L}^{-1}$ of $\mathrm{K}_{4}\left[\mathrm{Fe}(\mathrm{CN})_{6}\right]$ and $\mathrm{HNO}_{3} 0.5 \mathrm{~mol} \mathrm{~L}^{-1}$ at several scan rates (10$350 \mathrm{mV} \mathrm{s}^{-1}$ ) are shown in Figure $2 \mathrm{~A}$, denoting a reversible process between the redox couple $\mathrm{Fe}(\mathrm{CN})_{6}{ }^{4-} / \mathrm{Fe}(\mathrm{CN})_{6}{ }^{3-}$.

Table 2 summarizes the results of the linear plots of the current $I$ as a function of the square root of the scan rate $v^{1 / 2}$ and the logarithm of the current as a function of the logarithm of the scan rate obtained for SPAuE electrodes processed according to each one of the four tested protocols. Such plots can provide information about the area and roughness of the working 
electrodes. In general, the CV peak current $I_{p}$ (in A) of a diffusion-controlled reversible or quasi-reversible electrochemical reaction follows Randles-Sevcik equation [47] which at $25{ }^{\circ} \mathrm{C}$ is written in the form:

$$
\mathrm{I}_{\mathrm{p}}=2.69 \cdot 10^{5} \mathrm{n}^{3 / 2} \mathrm{~A} \mathrm{D}^{1 / 2} \mathrm{c} \mathrm{v}^{1 / 2}
$$

where $n$ is the number of electrons, $A$ is the electrode surface in $\mathrm{cm}^{2}, D$ is the diffusion coefficient of the analyte in $\mathrm{cm}^{2} \cdot \mathrm{s}^{-1}, c$ is the concentration in $\mathrm{mol} \cdot \mathrm{cm}^{-3}$ and $v$ is the scan rate in $V \cdot \mathrm{s}^{-1}$. Thus, the diffusion coefficient or the area of the electrode can be determined by plotting $I_{p} v s$. $v^{1 / 2}$ [48]. Table 2 shows the values calculated in this way for the area of SPAuE devices submitted to the four different treatments. It is important to remark that the mechanism studies show an $I_{d} / I_{c}$ ratio of approximately one, a characteristic of a quasi-reversible process and also supported by the $E_{a}-E_{c}$ values (Table $\mathrm{S} 1$ of supplementary material).

The comparison of the different pre-treatments described in Section 2.3.1 showed that mode D was not convenient, since the reference electrode suffered a serious damage after a few runs. As for treatments $B$ and $C$, they yielded a better performance than treatment $A$ (i.e., no treatment at all). Among these, condition B was more favorable than condition C since the peak currents were higher, indicating higher electrochemical response as seen in Figure 2B.

At an electrode surface both capacitive and faradaic processes coexist. The former are caused by the discharge of the electrode surface as a result of changes in the area size and a variation in the potential or by an adsorption process, whereas the latter are the result of electrochemical reactions at the electrode surface. Capacity is the non-faradaic current or the charge that is not used to oxidize or reduce the electroactive species and capacitance is defined as the ratio of charge stored to voltage applied [49]. Lower capacity values mean that less amount of charge is stored. Hence, more charge is available to participate in the redox reaction of the analyte.

Capacitance studies were done by obtaining cyclic voltammograms of the supporting electrolyte $\left(\mathrm{KNO}_{3} 0.5 \mathrm{~mol} \mathrm{~L}^{-1}\right)$. The double layer capacity $\left(C_{D L}\right)$ value was obtained from the slope of the regression line obtained when plotting the average (absolute) values of the anodic and cathodic current densities at different scan rates (from 10 to $350 \mathrm{mV} \mathrm{s}^{-1}$ ) versus the scan rate values. On the other hand, the observed capacity $\left(C_{o b s}\right)$ is defined as the ratio between the average anodic and cathodic current density to-and the scan rate (typically fixed at $100 \mathrm{mV} \mathrm{s}^{-1}$ ). In the calculations of both parameters, only the "smooth" part of the voltammograms was used since this corresponds to the region where faradaic currents prevail. The $C_{o b s}$ values for 
conditions $\mathrm{A}$ and $\mathrm{B}$ are below $0.70 \mathrm{mF} \mathrm{cm}^{-2}$ and the $C_{D L}$ values also lye on the same range, but pre-treated SPAuEs show significantly better reproducibility. This confirms the suitability of the treatment protocol B, which was used in the further measurements.

\subsection{Modifications of screen-printed electrodes with gold nanoparticles and carbon-based nanomaterials.}

Once the best treatment (B) for the SPAuE units was selected, several modifications were made with AuNPs and carbon-based nanomaterials. The AuNPs used were synthesized according to the method proposed by Cubillana-Aguilera et al. [33, 34], which employs ultrasounds, thus leading to nanoparticles also known as sononanoparticles. This method is fast, does not require stabilizers and does not use or produce toxic or hazardous solvents and wastes. The synthesis of the AuNPs by ultrasonication took less than 6 minutes and was confirmed by the red wine color of the solution due to the absorption of light by free electron oscillations (surface plasmon resonance (SPR) band) [50]. In order to verify that, the absorbance of the solution was scanned in the range $200-600 \mathrm{~nm}$ using UV-Vis spectroscopy. As shown by Haiss et al. [51], both size and concentration of AuNPs can be determined directly from UV-vis spectra as there is excellent agreement between experimental data and mean free path corrected theory. Moreover, surface plasmon resonance of AuNPs gives rise to an absorption band at $510-540 \mathrm{~nm}$ [52]. As Figure 3a shows, the synthesized AuNPs have a peak of absorption at $523 \mathrm{~nm}$. The absorbance maximum for spherical hydrosols with $12 \mathrm{~nm}$ of diameter appears at $518 \mathrm{~nm}$. A blue shift is expected for smaller colloids and a red-shift for larger ones [50].

TEM measurements (Figure S1, only two micrographs are shown) leaded to build the size distribution histogram corresponding to the AuNPs used in this work (see Figure 3b). From the histogram and the statistical treatment, it can be concluded that the synthesized nanoparticles have a narrow size distribution (Gaussian) with very homogeneous size, around $9 \pm 2 \mathrm{~nm}$, with more than $87 \%$ of the AuNPs with a size between 5 and $12 \mathrm{~nm}$, which is in consonance with the SPR band obtained. This result can be considered more precise and accurate than the average size \pm standard deviation value obtained from DLS measurements, where slightly bigger diameter due to the hydrodynamic size of the particles is estimated (11 $\pm 4 \mathrm{~nm}$ ). Besides, the information retrieved from the Digital Diffraction Pattern (DDP) built from the HREM image (Figure S1-C and B, respectively) allowed us to corroborate the composition of the nanoparticles, since the distance between planes in the reciprocal lattice is about $4.5 \mathrm{~nm}^{-1}$, which corresponds to a distance of approximately $2.2 \AA(0.22 \mathrm{~nm})$ in the real lattice, typical from [ $\left.\begin{array}{lll}1 & 1 & 1\end{array}\right]$ planes family of Au. The chemical composition of the AuNPs was also evidenced 
from the energy dispersive X-ray spectrum (Figure S1-D), where the peaks corresponding to $\mathrm{Au}$ are clearly visible, together with $\mathrm{C}, \mathrm{O}$ and $\mathrm{Cu}$ peaks from organic matter (citrate) capping the nanoparticles and the sample grid.

A drop of $35 \mu \mathrm{L}$ of the solution containing the synthesized AuNP was then deposited to the surface of pre-treated SPAuE and allowed to dry overnight at low temperature. SEM micrographs in Figure S2 demonstrate that AuNPs were successfully deposited onto the screen-printed electrode surface. According to micrographs A and B obtained with two different detectors (secondary and backscattered electrons detectors, respectively), different sized-AuNPs clusters are homogeneously dispersed onto the electrode surface. When increasing the magnification (micrographs $C$ and $D$ ), it can be observed (mainly in $D$, with backscattered electron detector) that together with the bigger clusters, numerous and well distributed small white dots stand out corresponding to non-agglomerated AuNPs.

The cyclic voltammogram obtained with the test $\mathrm{K}_{4}\left[\mathrm{Fe}(\mathrm{CN})_{6}\right]$ solution is shown in Figure $2 \mathrm{C}$ and the results of the mechanistic studies are included in Tables 2 and S1. The capacitance studies show relatively better reproducibility and repeatability for the SPAuE with AuNPs but, in general terms, the performance of the modified electrodes according to this method (that we will codify as EO) is not clearly better than that of bare units. This is why other strategies of modification with AuNPs were tried, including not only gold as a substrate, but also multiwalled carbon nanotubes (MWCNTs) and carbon nanofibers (CNFs). The code (from E1 to E16) and main features of each modification are summarized in Table 1, as well as a detailed description of the corresponding experimental procedures.

Concerning to modification E1, after the addition of MWCNTs to AuNPs followed by $10-15 \mathrm{~min}$ of stirring, a clear solution (with no red color due to the AuNPS SPR band) was obtained. The UV-vis spectra (not shown) of this uncolored solution confirmed the formation of the AuNPsMWCNTs nanocomposite [53] through the disappearance of the peak previously observed for AuNPs alone (Figure 3a). After that, redispersion of the AuNPs-MWCNTs nanocomposite was done using ultrasonic bath and then was deposited onto the pretreated SPAuE and allowed to dry overnight. SEM and TEM micrographs in Figure S3 clearly demonstrate that AuNPs were attached to the MWCNTs surface by using the proposed strategy. In SEM micrographs A and B, taken with secondary electrons and backscattered electrons detectors, respectively, several fiber-like formations corresponding to MWCNTs, covered with spherical-like particles representing AuNPs or small AuNPs agglomerates (more clearly evidenced in B), are shown. Moreover, in TEM micrographs $C$ and D (HREM and HAADF-STEM modes, respectively), an 
example of a MWCNT decorated with AuNPs (black and white particles, respectively, according to the TEM mode) can be observed. Hence, these micrographs provide evidences regarding the successful formation of the nanocomposite between MWCNTs and AuNPs and the joint catalytic effect of both nanomaterials in the nanocomposite should be expected. Figure S4, micrographs $A$ and $B$, also shows TEM images of the nanocomposite at higher magnification $(\times 95,000)$ at both TEM modes (HREM and HAADF-STEM modes, respectively). The micrograph $C$ is a zoom of the MWCNT/AuNPs nanocomposite tip appearing in micrograph $B$ and $D$ image represents the chemical characterization with compositional mapping of the MWCNT/AuNPs tip (shown in B). In this compositional map, the presence of Au (red) and C (blue) atoms can be observed, corresponding to AuNPs on the surface of MWCNTs, respectively.

Capacitance, mechanism and calibration studies were performed consequently after E1 modification of the SPAuE. The double layer capacitance values obtained with E1 were slightly higher than that of the SPAuE with AuNPs but still below $1.0 \mathrm{mF} \mathrm{cm}^{-2}$. As for the mechanism of the redox process, it was quasi-reversible and diffusion-controlled.

Modifications E2, E3 and E4 involved AuNPs in the presence of MWCNTs, AuNPs-polyaniline nanofibers or glutaraldehyde. Furthermore, commercial SPCNFE were tested as supporting electrode (see Table 1). Unfortunately, the deposited mixtures for E2, E3 and E4 easily disintegrated when carrying out CV scans; hence further studies with these modifications were not pursued.

Bare SPCNFE were used as E5 and also as a substrate in modifications E6 (electrodeposited gold) and E7 (drop-casted AuNPs), whereas modification E8 consisted on AuNPs deposited on a glassy carbon conventional solid electrode. Table 3 summarizes the values obtained for capacitance and mechanism studies. Further studies for other SPCNFE-based modifications (E9, E10 and E11) were not pursued due to the observed drastic changes in $C_{o b s}$ as a function of scan rate (not shown).

With pre-treated SPCNFE as transducer, E13 was modified with AuNPs mixed with MWCNTs (in Nafion ${ }^{\circledR}$ ) while in E14, gold was electrodeposited after drying the deposited MWCNTs (in Nafion ${ }^{\circledR}$ ). Electrodeposition was done following the procedures performed by Sharma et al. [54] where gold was electrodeposited with a potential step of +1.0 to $0.0 \mathrm{~V}$, scan rate of 50 $\mathrm{mV} / \mathrm{s}$ for 15 cycles and stored overnight at 0.1M PBS buffer ( $\mathrm{pH}$ 7.0). SPAuE were used as a substrate for E15 and E16, where AuNPs, MWCNTs and Nafion ${ }^{\circledR}$ were combined in different ways. Relatively large $C_{D L}$ values were obtained for electrodes E13, E14, E15 and E16, as seen in 
Table 4. Among these, modification E15 showed an especially good electrochemical behavior, thus, further trials were performed. Figure $2 \mathrm{C}$ shows CV signals obtained using E15.

\subsection{Application to CV measurements to Cysteine}

The most significant and promising modified electrodes studied in previous sections were applied to the determination of the aminothiol cysteine (Cys). The thiol functionality of Cys is increasingly protonated $\left(\mathrm{pK}_{\mathrm{a}}=8.4\right)$ as the $\mathrm{pH}$ of the solution is lowered, thus decreasing the nucleophilic character of the thiol moiety. However, at basic $\mathrm{pH}$ values there is an increased presence of the nucleophilic hydroxyl ions that compete with the less prevalent thiol, thereby reducing the response [16]. Therefore, a neutral $\mathrm{pH}$ of 7.0 achieved with PBS buffer was chosen for this study.

Calibration studies with Cys were first performed using electrodes modified according to E5, E6 and E7 protocols. However, no peaks of Cys were detected. Indeed, only four of all the electrode modifications discussed above provided acceptable results in the measurements with Cys and were considered in calibration studies. The chosen devices were: pre-treated SPAuE, SPAuE with AuNPs (EO), SPAuE with MWCNTs mixed with AuNPs (E1) and SPAuEwith MWCNTs in Nafion ${ }^{\circledR}$ mixed with AuNPs (E15). The voltammograms obtained for all four electrodes are shown in Figure 4. Table 4 summarizes the validation parameters calculated from the CV calibration data using three different pre-treated SPAuEs. Each data set consists of three parallel measurements for each level. The limit of detection (LOD) and the limit of quantitation (LOQ) were computed as three and ten times, respectively, the standard deviation of the intercept of the calibration line divided by the slope [55]

Table 4 shows that the calibration of cysteine using a bare SPAuE has reasonable reproducibility as shown by the coefficient of variation of the slope. The LOD and LOQ are somewhat higher than these obtained by Cavanillas et al. [16], but this is not strange, since CV measurements in steady state solutions are usually less sensitive that amperometric detection in LC. In this part of the study, CV analytical parameters are not intended for direct use in aminothiol analysis, but for comparing different electrodes with each other in order to select the most appropriate for amperometric detection in flow systems. Thus, Table 5 shows that AuNPs alone or mixed with MWCNTs improve the performance of bare SPAuE. As the features of both electrodes are similar, the simplest modification (that with AuNPs alone) was chosen for further amperometric LC studies. 


\subsection{Application to liquid chromatography (LC) measurements}

Preliminary FIA measurements confirmed the adequacy of the chosen electrodes to flow measurements and allowed us to select $+0.9 \mathrm{~V}$ as the most appropriate potential for amperometric detection. LC analyses were performed at room temperature with a mobile phase consisting of $0.05 \%$ TFA $(\mathrm{v} / \mathrm{v})$ in ultrapure filtered water (solvent $\mathrm{A}$ ) and methanol (solvent B). Ionic interactions between peptides and the stationary phase are minimized by trifluoroacetic acid (TFA) acting as a weak hydrophobic ion-pairing reagent that also maintains a low $\mathrm{pH}$. The flow rate used in the separation was $1.0 \mathrm{~mL} / \mathrm{min}$ and the injection volume was $10 \mu \mathrm{L}$. Under these conditions, separation of the aminothiols cysteine (Cys), homocysteine (hCys), glutathione (GSH) and methionine (Met) was achieved inside the concentration ranges $20-80 \mu \mathrm{mol} \mathrm{L}^{-1}$ for Cys, $2-10 \mu \mathrm{mol} \mathrm{L}^{-1}$ for Met and $5-30 \mu \mathrm{mol} \mathrm{L}^{-1}$ for GSH and hCys. Figure 5 shows typical amperometric chromatograms where the elution order is Cys, hCys, GSH and Met. Calibration was performed using synthetic solutions of aminothiols and produced the calibration lines shown in Figure 5 and the analytical parameters summarized in Table 5. When comparing these parameters with the corresponding values in [16] (see Table 5), an improvement is noticed as a consequence of the use of AuNPs, especially in the case of Cys. As for the other HPLC methods compared in Table 5, results are not too far from these achieved by UV and fluorescence detection [11, 12], but with no need of derivatization. Moreover, they are close to these obtained with a Ag disk [17] and better than in the case of graphene modified electrodes [46]. As for the amperometric method in [18], the results are difficult to compare with the present work, since the procedure for determining LOD and LOQ is based on the $\mathrm{S} / \mathrm{N}$ ratio, which, in our opinion, is much more favorable than ours, based on the standard deviation of the intercept. It must be pointed out that amperometric methods for HPLC detection of aminothiols are really scarce and that in the table we report the few works about the topic that we have found published during the last 10 years.

The method was successfully applied to the determination of Cys and Met in commercial dietary supplements containing these substances in its free-form, which means they are not connected in peptide bonds with other amino acids. Table 6 summarizes these good results.

\section{Conclusions}

In this paper, commercially available screen-printed gold electrodes were successfully modified with AuNPs (about $11 \mathrm{~nm}$ of diameter) synthesized via ultrasonication with a high energy ultrasound probe in order to determine aminothiols. Many different electrode 
configurations including MWCNTs, AuNPs-MWCNTs nanocomposites and carbon nanofibers screen-printed electrodes were tested, obtaining the highest stability and the best electrochemical results in terms of sensitivity and reproducibility with drop-casted AuNPs onto SPAuEs. This fact demonstrates that the unique properties of AuNPs enhance electrochemical responses with respect to conventional electrodes. This electrode configuration was applied to determine several aminothiols, such as cysteine, methionine, glutathione and homocysteine, first individually and later jointly, obtaining very good results. Moreover, when the proposed sensor was used as amperometric detector after LC separation, and according to literature, the quality analytical parameters for the determination of these aminothiols, especially for Cys, was further improved. The method was also successfully applied to the quantification of Cys and Met in dietary supplements with excellent recoveries.

\section{Acknowledgements}

Valeree Bernardo Boongaling thanks the European Commission (EACEA) for supporting her study and research activity inside the Erasmus Mundus Master in Quality in Analytical Laboratories (EMQAL) through an Erasmus Mundus studentship (SGA 2015-1992, FPA 20130225). J.J. García-Guzmán greatly acknowledges ESF funds, Sistema de Garantía Juvenil depending on Ministerio de Empleo y Seguridad Social of Spain and Junta de Andalucía for his employment contract (E-11-2017-0397859). UCA authors also acknowledge Junta de Andalucía (PAIDI 2017) and Institute of Research on Electron Microscopy and Materials (IMEYMAT) for their financial support. UB authors acknowledge Generalitat de Catalunya for the project 2017 SGR311. 


\section{References}

[1] J.J. García-Guzmán, D. López-Iglesias, M. Marin, C. Lete, S. Lupu, J.M. PalaciosSantander, L. Cubillana-Aguilera, Electrochemical Biosensors for Antioxidants, in Advanced Biosensors for Health Care Applications, 1st Ed., D. Inamuddin, R. Khan, A. Mohammad, A.M. Asiri (Eds.), Elsevier, 2019. ISBN: 9780128157435.

[2] A. Masek, E. Chrzescijanska, M. Zaborski, Estimation of the Antioxidative Properties of Amino Acids - an Electrochemical Approach, Int. J. Electrochem. Sci. 9 (2014) 7904-7915.

[3] A. Khan, Z. Iqbal, Y Shah, L. Ahmad, S. Nazir, D.G. Watson, J.A. Khan, A. Khan, A. Ismail, New HPLC Method for the Simultaneous Determination of Ascorbic Acid and Aminothiols in Human Plasma and Erythrocytes Using Electrochemical Detection. Talanta 84 (2011) 789-801.

[4] R. Ferin, M.L. Pavão, J. Baptista, Methodology for a Rapid and Simultaneous Determination of Total Cysteine, Homocysteine, Cysteinylglycine and Glutathione in Plasma by Isocratic RP-HPLC, J. Chromatog. B 911 (2012) 15-20.

[5] W.A. Kleinman, J.J. Richie, Determination of Thiols and Disulfides Using HighPerformance Liquid Chromatography with Electrochemical Detection. J. Chromatog. B 672 (1995) 73-80.

[6] D. Perevezentseva, K. Skirdin, E. Gorchakov, V. Bimatov, Electrochemical Activity of Methionine at Graphite Electrode Modified with Gold Nanoparticles, Key Eng. Mater. 685 (2016) 563-568.

[7] J.B. Raoof, R. Ojani, Z. Mohammadpour, Homogeneous Electrocatalytic Oxidation and Voltammetric Determination of L-Cysteine by 1,1'-Ferrocenedicarboxylic Acid at Glassy Carbon Electrode, Anal. Bioanal. Electrochem. 2 (2010) 24-35.

[8] L.H. Wang, W.S. Huang, Electrochemical Oxidation of Cysteine at a Film Gold Modified Carbon Fiber Microelectrode Its Application in a Flow-Through Voltammetric Sensor, Sensors 12 (2012) 3562-3577.

[9] H. Karimi-Maleh, M. Keyvanfard, K. Alizad, V. Khosravi, M. Asnaashariisfahani, Electrocatalytic Determination of Glutathione Using Multiwall Carbon Nanotubes Paste Electrode as a Sensor and Isoprenaline as a Mediator, Int. J. Electrochem. Sci. 7 (2012) 6816-6830.

[10] R.F. Grimble, A.A. Jackson, C. Persaud, M.J. Wride, F. Delers, R. Engler, Cysteine and Glycine Supplementation Modulate the Metabolic Response to Tumor Necrosis Factor \{Alpha\} in Rats Fed a Low Protein Diet, J. Nutr. 122 (1992) 2066-2073.

[11] W. Zhang, P. Li, Q. Geng, Y. Duan, M. Guo, Y. Cao, Simultaneous Determination of Glutathione, Cysteine, Homocysteine, and Cysteinylglycine in Biological Fluids by lonPairing High-Performance Liquid Chromatography Coupled with Precolumn Derivatization, J. Agric. Food Chem. 62 (2014) 5845-5852.

[12] R. Ferin, M.L. Pavão, J. Baptista, Methodology for a Rapid and Simultaneous Determination of Total Cysteine, Homocysteine, Cysteinylglycine and Glutathione in Plasma by Isocratic RP-HPLC, J. Chromatog. B 911 (2012) 15-20. 
[13] X. Hu, B. Mutus, Electrochemical Detection of Sulfide, Rev. Anal. Chem. 32 (2013) 247256.

[14] M. Hanko, L. Švorc, A. Planková, P. Mikuš, Overview and Recent Advances in Electrochemical Sensing of Glutathione. A review, Anal. Chim. Acta 1062 (2019) 1-27.

[15] R.H.P. Pedroza, N. Serrano, J.M. Díaz-Cruz, C. Ariño, M. Esteban, Integration of Commercial Screen-printed Electrodes into a Voltammetric Electronic Tongue for the Analysis of Aminothiols, Electroanalysis 28 (2016) 1570-1577.

[16] S. Cavanillas, N. Serrano, J.M. Díaz-Cruz, C. Ariño, M. Esteban, Commercial ScreenPrinted Gold Electrodes for the Detection and Quantification of Aminothiols in Human Plasma by Liquid Chromatography with Electrochemical Detection. Electroanalysis 26 (2014) 581-587.

[17] A. Sarakbi, Z. Aydogmus, A. Dago, D. Mertens, J.Y. Dewert, J.M. Kauffmann, Determination of Aminothiols by Liquid Chromatography with Amperometric Detection at a Silver Electrode: Application to White Wines, Anal. Chim. Acta 786 (2013) 22- 28.

[18] A. Khan, M.I. Khan, Z. Iqbal, Y. Shah, L. Ahmad, S. Nazir, D.G. Watson, J.A. Khan, F. Nasir, A. Khan, Ismail, A New HPLC Method for the Simultaneous Determination of Ascorbic Acid and Aminothiols in Human Plasma and Erythrocytes using Electrochemical Detection, Talanta 84 (2011) 789-801.

[19] M.I. Khan, Z. Iqbal, Simultaneous Determination of Ascorbic acid, Aminothiols, and Methionine in Biological Matrices using Ion-Pairing RP-HPLC Coupled with Electrochemical Detector, J. Chromatog. B 879 (2011) 2567- 2575.

[20] Y. Tahara, K. Toko, Electronic Tongues-A Review, IEEE Sens. J., 13 (2013) 3001-3011.

[21] M. del Valle, Electronic Tongues Employing Electrochemical Sensors, Electroanalysis 22 (2010) 1539-1555.

[22] C. Pérez-Ràfols, A. Gómez, N. Serrano, J.M. Díaz-Cruz, C. Ariño, M. Esteban, A Voltammetric Electronic Tongue Based on Commercial Screen-Printed Electrodes for the Analysis of Aminothiols by Differential Pulse Voltammetry, Electroanalysis 29 (2017) 1559-1565.

[23] C.Y. Liao, J.M. Zen, Development of a Method for Total Plasma Thiols Measurement Using a Disposable Screen-printed Carbon Electrode Coupled with a $\mathrm{MnO}_{2}$ Reactor. Sens. Actuator B 129 (2008) 896-902.

[24] F.W. Campbell, R.G. Compton, The Use of Nanoparticles in Electroanalysis: an Updated Review, Anal. Bioanal. Chem 396 (2010) 241-259.

[25] W. Siangproh, W. Dungchai, P. Rattanarat, O. Chailapakul, Nanoparticle-based Electrochemical Detection in Conventional and Miniaturized Systems and their Bioanalytical Applications: A Review, Anal. Chim. Acta 690 (2011) 10-25.

[26] C. Zhu, G. Yang, H. Li, D. Du,Y. Lin, Electrochemical Sensors and Biosensors Based on Nanomaterials and Nanostructures, Anal. Chem. 87 (2015) 230-249.

[27] M. Larguinho, P.V. Baptista, Gold and Silver Nanoparticles for Clinical Diagnostics From Genomics to Proteomics, J. Proteomics, 75 (2012) 2811-2823. 
[28] Z. Taleat, A. Khoshroo, M. Mazloum-Ardakani, Screen-printed Electrodes for Biosensing: A Review (2008-2013), Microchim. Acta 181 (2014) 865-891.

[29] R.A.S. Couto, J.L.F.C. Lima, M.B. Quinaz, Recent Developments, Characteristics and Potential Applications of Screen-printed Electrodes in Pharmaceutical and Biological Analysis, Talanta 146 (2016) 801-814.

[30] A. Hayat, J.L. Marty, Disposable Screen-printed Electrochemical Sensors: Tools for Environmental Monitoring, Sensors 14 (2014) 10432-10453.

[31] F. Arduini, L. Micheli, D. Moscone, G. Palleschi, S. Piermarini, F. Ricci, G. Volpe. Electrochemical Biosensors Based on Nanomodified Screen-printed Electrodes: Recent Applications in Clinical Analysis. Trends Anal. Chem. 79 (2016) 114-126.

[32] M. Trojanowicz, Impact of Nanotechnology on Design of Advanced Screen-printed Electrodes for Different Analytical Applications. Trends Anal. Chem. 84 (2016) 22-47.

[33] Cubillana-Aguilera, L. M., Franco-Romano, M., Gil, M. L. A., Naranjo-Rodríguez, I., De Cisneros, J. H. H., Palacios-Santander, J. M. New, fast and green procedure for the synthesis of gold nanoparticles based on sonocatalysis. Ultrasonics Sonochemistry, 18(3) (2011) 789-794.

[34] M. Franco-Romano, M.L.A. Gil, J.M. Palacios-Santander, J.J. Delgado-Jaén, I. NaranjoRodríguez, J.L. Hidalgo-Hidalgo de Cisneros, L.M. Cubillana-Aguilera, Sonosynthesis of Gold Nanoparticles from a Geranium Leaf Extract, Ultrasonics Sonochemistry 21 (2014) 1570-1577.

[35] S.K. Srikar, D.D. Giri, D.B. Pal, P.K. Mishra, S.N. Upadhyay, Green Synthesis of Silver Nanoparticles: A Review, Green Sustainable Chem. 6 (2016) 34-56.

[36] J. Bastos-Arrieta, A. Florido, Clara Pérez-Ràfols , N. Serrano, N. Fiol, J. Poch, I. Villaescusa, Green Synthesis of Ag Nanoparticles Using Grape Stalk Waste Extract for the Modification of Screen-Printed Electrodes, Nanomaterials 8 (2018) 946.

[37] S. Guo, E. Wang, Synthesis and Electrochemical Applications of Gold Nanoparticles, Anal. Chim. Acta 598 (2007) 181-192.

[38] C. Ajaero, M.Y.M. Abdelrahim, J.M. Palacios-Santander, M.L. Almoraima-Gil, I. NaranjoRodríguez, J.L. Hidalgo-Hidalgo de Cisneros, L.M. Cubillana-Aguilera, Comparative Study of the Electrocatalytic Activity of Different Types of Gold Nanoparticles using SonogelCarbon Material as Supporting Electrode, Sens. Actuat. B-Chem. 171-172 (2012) 12441256.

[39] A. Attar, L. Cubillana-Aguilera, I. Naranjo-Rodríguez, J.L. Hidalgo-Hidalgo de Cisneros, J. M. Palacios-Santander, A. Amine, Amperometric Inhibition Biosensors based on Horseradish Peroxidase and Gold Sononanoparticles Immobilized onto Different Electrodes for Cyanide Measurements, Bioelectrochemistry 101 (2015) 84-91.

[40] Y. Zhang, A. Yang, X. Zhang, H. Zhao, X. Li, Z. Yuan, Highly Selective and Sensitive Biosensor for Cysteine Detection based on in situ Synthesis of Gold Nanoparticles/Graphene Nanocomposites, Colloids and Surfaces A: Physicochem. Eng. Aspects 436 (2013) 815- 822.

[41] L.A. Goulart, R. Gonçalves, A. Alves Correa, E. Chaves Pereira, L.H. Mascaro, Synergic Effect of Silver Nanoparticles and Carbon Nanotubes on the Simultaneous Voltammetric 
Determination of Hydroquinone, Catechol, Bisphenol A and Phenol, Microchim. Acta 185 (2018) 12.

[42] H. Wan, Q. Sun, H. Li, F. Sun, N. Hu, P. Wang, Screen-printed Gold Electrode with Gold Nanoparticles Modification for Simultaneous Electrochemical Determination of Lead and Copper. Sens. Actuat. B-Chem. 209 (2015) 336-342.

[43] C. Pérez-Ràfols, J. Bastos-Arrieta, N. Serrano, J.M. Díaz-Cruz, C. Ariño, J. de Pablo, M. Esteban, Ag Nanoparticles Drop-Casting Modification of Screen-Printed Electrodes for the Simultaneous Voltammetric Determination of $\mathrm{Cu}(\mathrm{II})$ and $\mathrm{Pb}(\mathrm{II})$, Sensors 17 (2017) 1458.

[44] X. Luo, A. Morrin, A.J. Killard, M.R. Smyth, Application of Nanoparticles in Electrochemical Sensors and Biosensors, Electroanalysis 18 (2006) 319-326.

[45] R. Garcia-González, M.T. Fernandez-Abedul, A. Pernia, A. Costa-Garcia, Electrochemical Characterization of Different Screen-printed Gold Electrodes. Electrochim. Acta 53 (2008) 3242-3249.

[46] A. Dago, J. Navarro, C. Ariño, J.M. Díaz-Cruz, M. Esteban, Carbon Nanotubes and Graphene Modified Screen-Printed Carbon Electrodes as Sensitive Sensors for the Determination of Phytochelatinsin Plants Using Liquid Chromatography with Amperometric Detection, J. Chromatog. A 1409 (2015) 210-217.

[47] A.J. Bard, L.R. Faulkner, Electrochemical Methods: Fundamentals and Applications, 2nd ed., Wiley, New York, 2001.

[48] A.A. Aljabali, J.E. Barclay, J.N. Butt, G.P. Lomonossoff, D.J. Evans, Redox-active Ferrocene-modified Cowpea Mosaic Virus Nanoparticles. Dalton transactions, 39 (2010) 7569-7574.

[49] P.H. Rieger, Electrochemistry, 2nd Ed., Chapman \& Hall, Inc., USA, 1994.

[50] C.D. Keating, M.D. Musick, M.H. Keefe, M. J. Natan, Kinetics and Thermodynamics of Au Colloid Monolayer Self-Assembly: Undergraduate Experiments in Surface and Nanomaterials Chemistry, J. Chem. Educ. 76 (1999) 949-955.

[51] W. Haiss, N.T. Thanh, J. Aveyard, D.G. Fernig, Determination of Size and Concentration of Gold Nanoparticles from UV- Vis Spectra. Anal. Chem. 79 (2007) 4215-4221.

[52] R. Puddephatt, The Chemistry of Gold, Elsevier, 1978.

[53] M.Y.M. Abdelrahim, S.R. Benjamin, L.M. Cubillana-Aguilera, I. Naranjo-Rodríguez, J.L. Hidalgo-Hidalgo de Cisneros, J.J. Delgado, J.M. Palacios-Santander, Study of the Electrocatalytic Activity of Cerium Oxide and Gold-Studded Cerium Oxide Nanoparticles Using a Sonogel-Carbon Material as Supporting Electrode: Electroanalytical Study in Apple Juice for Babies, Sensors 13 (2013) 4979-5007.

[54] M.K. Sharma, V.K. Rao, G.S. Agarwal, G.P. Rai, N.G.S. Prakash, S.K. Sharma, R. Vijayaraghavan, Highly Sensitive Amperometric Immunosensor for Detection of Plasmodium falciparum Histidine-Rich Protein 2 in Serum of Humans with Malaria: Comparison with a Commercial Kit, J. Clinical Micobiol. 46 (2008) 3759-3765.

[55] J.N. Miller, J.C. Miller, Statistics and Chemometrics for Analytical Chemistry, 6th Ed., Pearson Education/Prentice Hall, United Kingdom, 2010. 
Figure 1

Chemical structures of the aminothiols considered in the present study.<smiles>N[C](CS)C(=O)O</smiles>

Cysteine<smiles>N[C@@H](CCS)C(=O)O</smiles>

Homocysteine<smiles>CSCCC(N)C(=O)O</smiles>

Methionine<smiles>N[C@@H](CCC(=O)NC(CS)C(=O)NCC(=O)O)C(=O)O</smiles>

Glutathione 
Figure 2

Cyclic voltammograms measured at different scan rates (from 10 to $400 \mathrm{mV} \cdot \mathrm{s}^{-1}$ ) in a $5.0 \mathrm{mmol}$ $\mathrm{L}^{-1}$ of $\mathrm{K}_{4}\left[\mathrm{Fe}(\mathrm{CN})_{6}\right]$ and $\mathrm{HNO}_{3} 0.5 \mathrm{~mol} \mathrm{~L}^{-1}$ solution using a bare SPAuE (A), a SPAuE device preconditioned according to method B (See Section 2.3.1) and modified with AuNPs (B) and a SPAuE device modified with MWCNTs in Nafion ${ }^{\circledR}$ mixed with AuNPs according to the protocol E15 (C) (See Table 1).
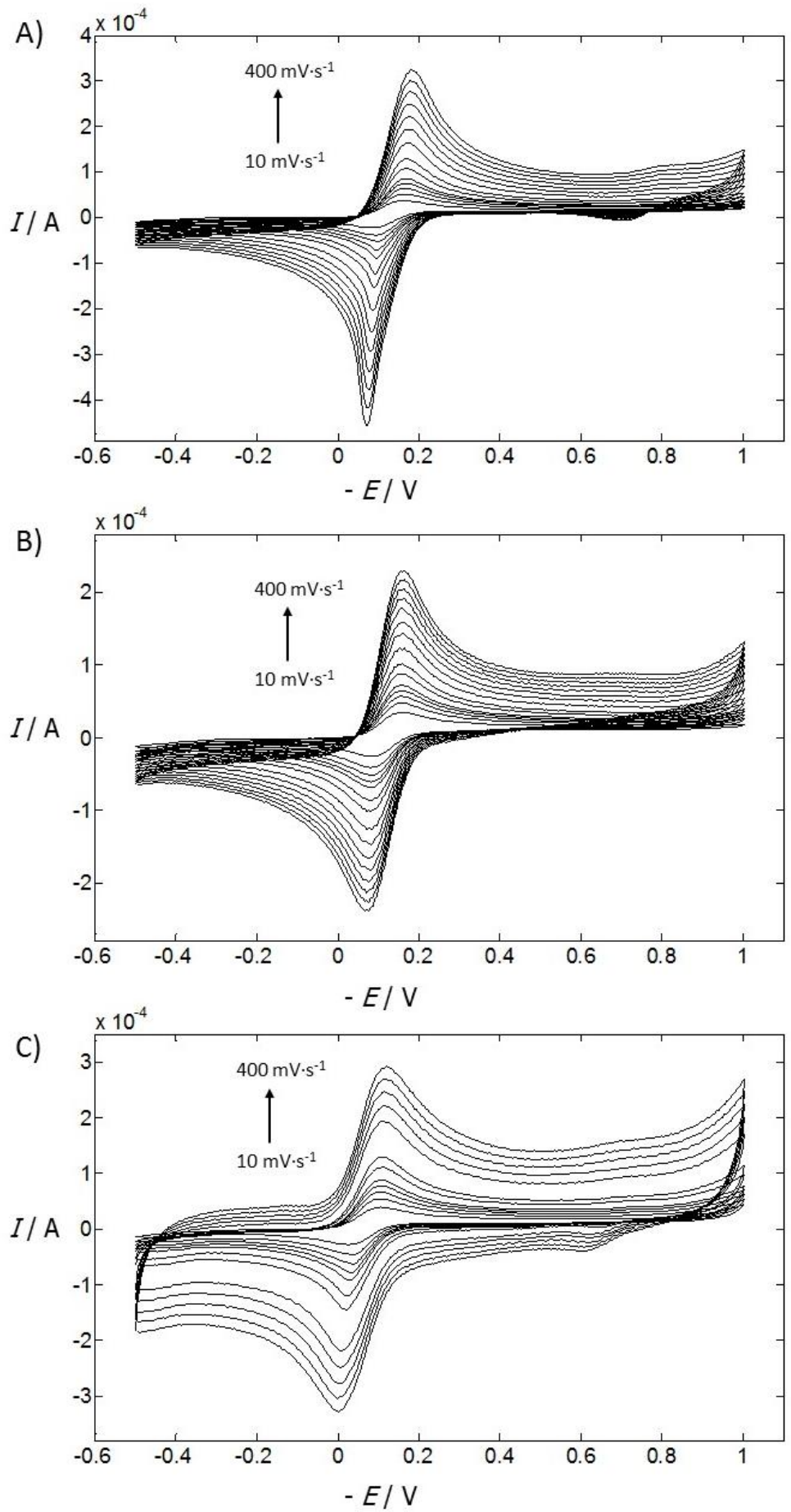
Figure 3

UV-vis absorption spectrum (A) and size distribution from TEM measurements (B) of the synthesized AuNPs.

A)

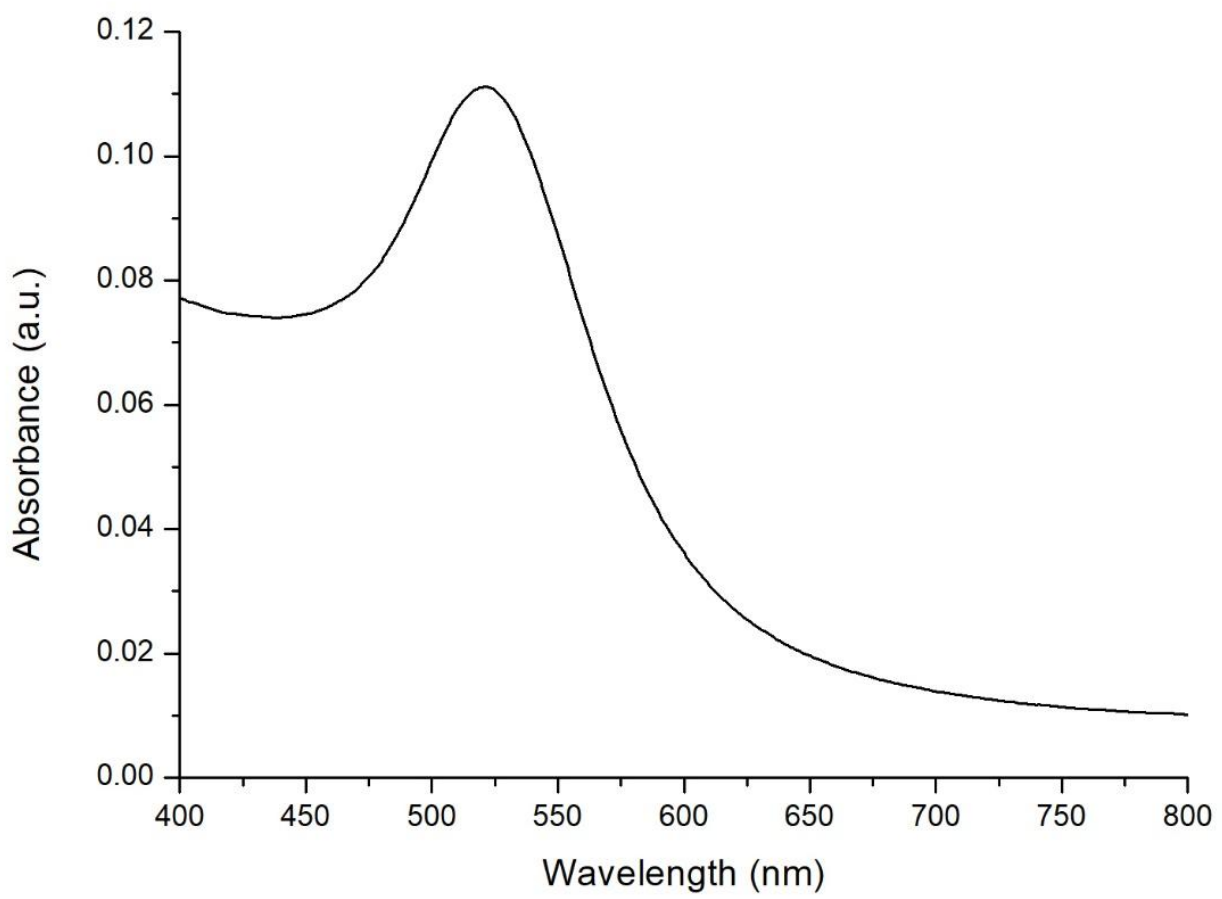

B)

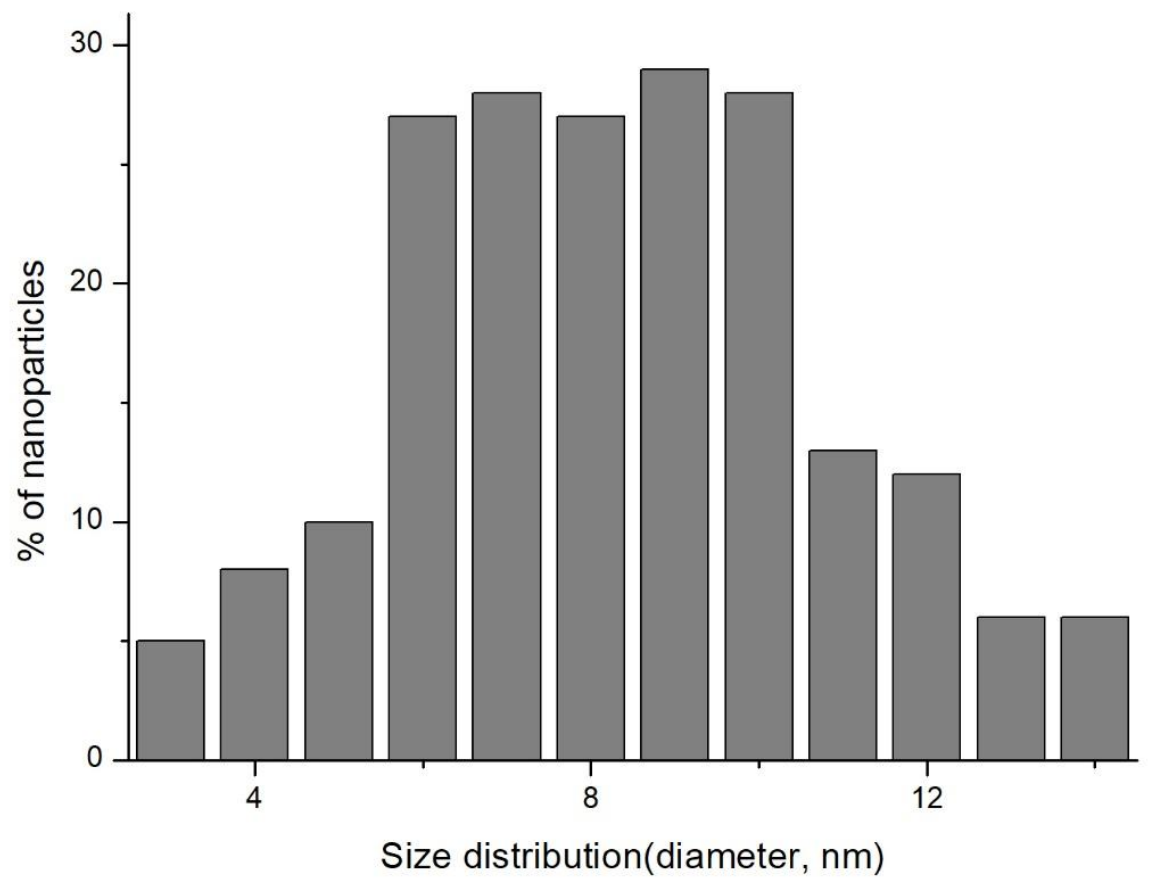


Figure 4

Cyclic voltammograms for cysteine calibration using different electrodes: (A) pre-treated gold screen-printed electrode, (B) gold screen-printed electrode with gold nanoparticles, (C) gold screen-printed electrode with multi-walled carbon nanotubes mixed with gold nanoparticles and (D) gold screen-printed electrode with multi-walled carbon nanotubes in Nafion ${ }^{\circledR}$ mixed with gold nanoparticles (E15). Supporting electrolyte: PBS buffer, pH 7.0.
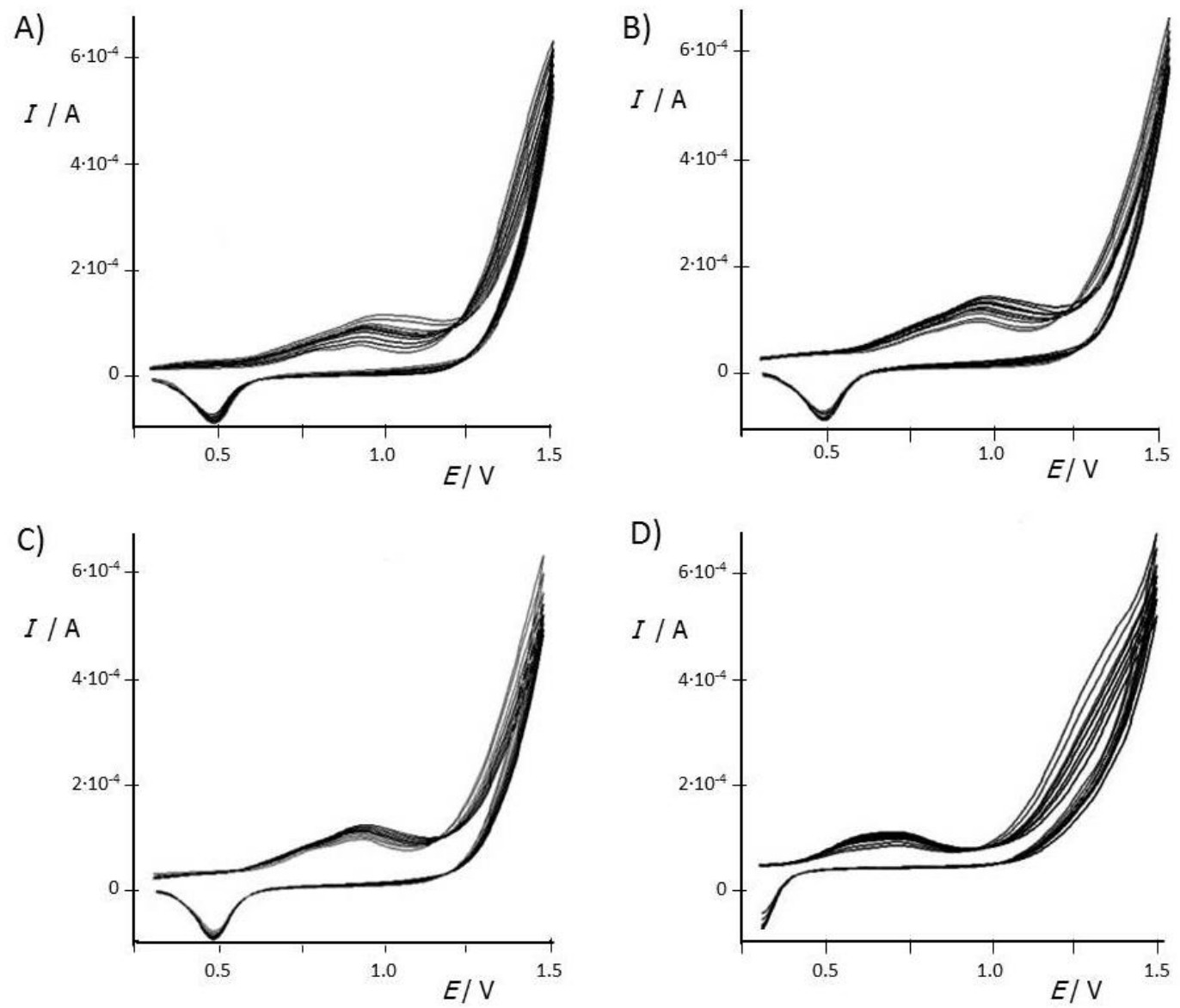
Figure 5

Typical amperometric chromatograms obtained for synthetic mixtures of aminothiols $(A)$ and calibration lines (including 95\% confidence intervals and the determination coefficient $\mathrm{R}^{2}$ ) obtained by LC-EC for Cysteine (B), methionine (C), glutathione (D) and homocysteine (E).
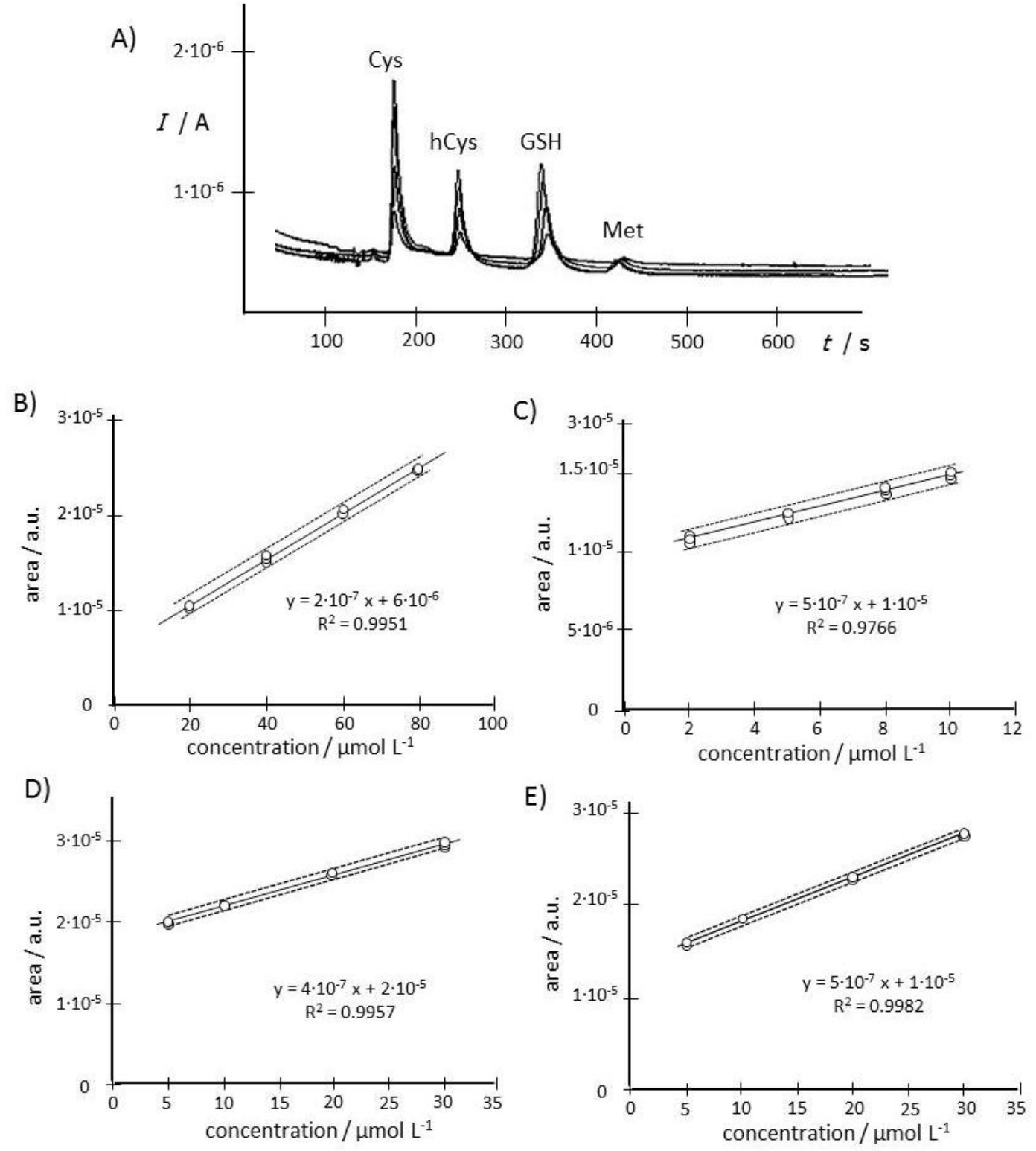
Table 1

List of SPAuE modifications with gold nanoparticles (AuNP) and the procedures for their preparation

\begin{tabular}{|c|c|c|}
\hline Name & Type of electrode & Preparation Procedure \\
\hline EO & SPAuE + AuNPs deposited & $\begin{array}{l}\text { Pre-treated SPAuE where } 5 \mu \mathrm{L} \text { of AuNPs colloidal solution was } \\
\text { deposited and allowed to dry overnight }\end{array}$ \\
\hline E1 & $\begin{array}{l}\text { SPAuE + MWCNTs mixed } \\
\text { with AuNPs }\end{array}$ & $\begin{array}{l}50 \mathrm{mg} \text { of MWCNT was added to } 1.5 \mathrm{~mL} \text { of AuNPs colloidal solution } \\
\text { and stirred for } 10-15 \text { minutes. The clear layer was subjected to UV- } \\
\text { VIS to check the disappearance of the SPR band from AuNPs. } \\
\text { Resuspension was done using ultrasonic bath. To the pretreated } \\
\text { SPAuE, } 5 \mu \text { was deposited and allowed to dry overnight. }\end{array}$ \\
\hline E2 & $\begin{array}{l}\text { SPAuE + MWCNTs in } \\
\text { ethanol }\end{array}$ & $\begin{array}{l}33 \mathrm{mg} \text { of MWCNTs was added to } 1 \mathrm{~mL} \text { of ethanol, then stirred for } \\
30 \mathrm{~min} \text { and sonicated for } 30 \mathrm{~min} .5 \mu \mathrm{l} \text { was deposited onto the } \\
\text { electrode surface and allowed to dry overnight. }\end{array}$ \\
\hline E3 & $\begin{array}{l}\text { SPAuE + MWCNTs + AuNPs- } \\
\text { PANI nanocomposite }\end{array}$ & $\begin{array}{l}\text { Nanocomposite was made by rapidly adding } 12 \mu \mathrm{L} \text { of } 26 \mathrm{mM} \\
\text { aniline to } 5 \mathrm{~mL} \text { of } \mathrm{KAuCl}_{4} \text { in } 0.5 \mathrm{mM} \text { of } \mathrm{LiClO}_{4} \text { solution. This was } \\
\text { sonicated for } 5 \text { minutes with potential high energy ultrasound } \\
\text { probe and then allowed to dry for } 24 \mathrm{~h} \text {. } 5 \mu \text { l was deposited onto } \\
\text { the electrode surface and allowed to dry overnight. }\end{array}$ \\
\hline E4 & $\begin{array}{l}\text { SPAuE + MWCNTs + } \\
\text { gluteraldehyde }\end{array}$ & $\begin{array}{l}\text { To } 50 \mu \mathrm{L} \text { of AuNPs colloidal solution, } 1.67 \mathrm{mg} \text { of MWCNTs and } 5 \mu \mathrm{L} \\
\text { gluteraldehyde was added. Then, } 5 \mu \mathrm{l} \text { was deposited onto the } \\
\text { electrode surface and allowed to dry overnight. }\end{array}$ \\
\hline E5 & CNFs (bare) & Bare CNFs SPE. \\
\hline E6 & CNFs + Au electrodeposited & Electrodeposition of Au was done to a bare CNF SPE. \\
\hline E7 & $\begin{array}{l}\text { CNFs + Au electrodeposited } \\
+ \text { AuNPs deposited }\end{array}$ & $\begin{array}{l}\text { To a bare CNFs SPE } 5 \mu \mathrm{L} \text { of AuNPs colloidal solution was deposited } \\
\text { and allowed to dry overnight. }\end{array}$ \\
\hline E8 & GCE + AuNPs deposited & $\begin{array}{l}\text { To a Glassy carbon electrode, } 5 \mu \mathrm{L} \text { of AuNPs colloidal solution was } \\
\text { deposited and allowed to dry overnight }\end{array}$ \\
\hline E9 & $\begin{array}{l}\text { CNFs (no pretreat) }+ \\
\text { MWCNTs in } 5 \% \text { Nafion }^{\circledR}+ \\
\text { AuNPs }\end{array}$ & $\begin{array}{l}3 \mathrm{mg} \text { of MWCNTs-COOH was added to } 3 \mathrm{~mL} \text { of } 5 \% \text { Nafion }{ }^{\circledR} \text { and } \\
\text { sonicated for proper mixing. In a bare CNFs SPE, } 5 \mu \mathrm{L} \text { of the } \\
\text { Nafion }{ }^{\circledR}-\mathrm{MWCNTs} \text { mixture was deposited and allowed to dry for } 2 \\
\text { h. After which, } 5 \mu \mathrm{L} \text { of AuNPs colloidal solution was deposited and } \\
\text { allowed to dry overnight. }\end{array}$ \\
\hline E10 & $\begin{array}{l}\text { CNFs (w/ pretreat) }+ \\
\text { MWCNTs in } 5 \% \text { Nafion }^{\circledR}+ \\
\text { AuNPs }\end{array}$ & $\begin{array}{l}\text { CNFs SPE was initially pretreated with } 0.1 \mathrm{M} \mathrm{NaOH} \text { at } 1.5 \mathrm{~V} \text { for } 5 \\
\text { minutes. Then subsequent steps are the same as } \mathrm{E} 4 \text {. }\end{array}$ \\
\hline E11 & $\begin{array}{l}\text { CNFs (w/ pretreat) }+ \\
\text { MWCNTs in } 5 \% \text { Nafion }{ }^{\circledR}+ \\
\text { Au electrodeposited }\end{array}$ & $\begin{array}{l}\text { Initial steps of preparation as E10, but Au was electrodeposited } \\
\text { with a potential step of }+1.0 \text { to } 0.0 \mathrm{~V} \text {, scan rate of } 50 \mathrm{mV} / \mathrm{s} \text { for } 15 \\
\text { cycles and stored overnight at } 0.1 \mathrm{M} \text { PBS buffer }(\mathrm{pH} 7.0) \text {. }\end{array}$ \\
\hline E12 & $\begin{array}{l}\text { SPAuE + MWCNTs in 5\% } \\
\text { Nafion }^{\circledR}\end{array}$ & $\begin{array}{l}5 \mu \mathrm{L} \text { of } 1 \mathrm{mg} / \mathrm{mL} \text { MWCNTs-COOH in } 5 \% \mathrm{Nafion}^{\circledR} \text { was deposited } \\
\text { onto a pre-treated SPAuE and allowed to stand overnight at low } \\
\text { temperature. }\end{array}$ \\
\hline E13 & $\begin{array}{l}\text { CNFs (w/ pretreat) }+ \\
\text { MWCNTs in Nafion }{ }^{\circledR} \text { mixed } \\
\text { with AuNPs }\end{array}$ & $\begin{array}{l}\text { A mixture was made consisting of } 100 \mu \mathrm{L} \text { of } \text { Nafion }^{\circledR}, 400 \mu \mathrm{L} \text { of } \\
\text { AuNPs colloidal solution and } 2.5 \mathrm{mg} \text { of MWCNTs. To a pre-treated } \\
\text { CNFs SPE, } 5 \mu \mathrm{L} \text { of this mixture was deposited and allowed to dry }\end{array}$ \\
\hline
\end{tabular}




\begin{tabular}{|l|l|l|}
\hline E14 & $\begin{array}{l}\text { CNFs (w/ pretreat) }+ \\
\text { MWCNTs in Nafion }{ }^{\circledR}+\mathrm{Au} \\
\text { electrodeposited }\end{array}$ & $\begin{array}{l}\text { A mixture was made consisting of } 200 \mu \mathrm{L} \text { of Nafion }{ }^{\circledR}, 800 \mu \mathrm{L} \text { of } \\
\text { ethanol and } 5.0 \mathrm{mg} \text { of MWCNTs. To a pre-treated CNFs SPE, } 5 \mu \mathrm{L} \\
\text { of this mixture was deposited and allowed to dry for } 2 \mathrm{~h} \text { prior to } \\
\text { electrodepositing gold on its surface. }\end{array}$ \\
\hline E15 & $\begin{array}{l}\text { SPAuE + MWCNTs in } \\
\text { Nafion }{ }^{\circledR} \text { mixed with AuNPs }\end{array}$ & $\begin{array}{l}\text { The same E13 mixture was deposited onto the surface of a pre- } \\
\text { treated SPAuE and allowed to dry overnight. }\end{array}$ \\
\hline E16 & $\begin{array}{l}\text { SPAuE + MWCNTs in } \\
\text { Nafion }\end{array}{ }^{\circledR}$ with ethanol & $\begin{array}{l}\text { The same E14 mixture was deposited onto the surface of a pre- } \\
\text { treated SPAuE and allowed to dry overnight. }\end{array}$ \\
\hline
\end{tabular}

SPAuE: screen-printed gold electrode; AuNPs: gold nanoparticles obtained via ultrasonication with a high energy ultrasound probe; MWCNTs: multiwalled carbon nanotubes; SPR: surface plasmon resonance; PANI: polyaniline; CNFs SPE: carbon nanofibers screen-printed electrode; GCE: glassy-carbon electrode; MWCNTs-COOH: carboxilated multiwalled carbon nanotubes; PBS: phosphate buffer solution. 
Table 2

Results of the linear plots of the current $(I)$ versus the square root of the scan rate $\left(v^{1 / 2}\right)$ and the logarithm of the current $(\log I)$ versus the logarithm of the scan rate $(\log v)$ obtained in the $\mathrm{CV}$ measurements of a $5.0 \mathrm{mmol} \mathrm{L}^{-1}$ of $\mathrm{K}_{4}\left[\mathrm{Fe}(\mathrm{CN})_{6}\right]$ solution with bare SPAuE submitted to treatments $A, B, C$ and $D$ and SPAuE treated according to $B$ and further modified with AuNPs. For every plot, the values of the slope, the intercept and the determination coefficient $\left(R^{2}\right)$ are given. The average areas obtained from these plots are also shown.

\begin{tabular}{|c|c|c|c|c|c|c|c|c|c|c|}
\hline \multirow{2}{*}{$\begin{array}{l}\text { Treat- } \\
\text { ment }\end{array}$} & \multicolumn{3}{|c|}{$I$ vs. $v^{1 / 2}$ (anodic current) } & \multicolumn{3}{|c|}{$I$ vs. $v^{1 / 2}$ (cathodic current) } & \multicolumn{3}{|c|}{$\log I$ vs. $\log v($ anodic $)$} & \multirow{2}{*}{$\begin{array}{l}\text { Average } \\
\text { area } \\
\left(\mathrm{cm}^{2}\right)\end{array}$} \\
\hline & Intercept & Slope & $R^{2}$ & Intercept & Slope & $\mathrm{R}^{2}$ & Intercept & Slope & $\mathrm{R}^{2}$ & \\
\hline$A$ & $-2 \times 10^{-6}$ & $4 \times 10^{-4}$ & 0.999 & $5 \times 10^{-6}$ & $-4 \times 10^{-4}$ & 0.999 & -3.4 & 0.51 & 0.999 & 0.112 \\
\hline$B$ & $-1 \times 10^{-4}$ & $1 \times 10^{-3}$ & 0.991 & $1 \times 10^{-3}$ & $-1 \times 10^{-3}$ & 0.990 & -3.4 & 0.50 & 0.999 & 0.239 \\
\hline$C$ & $-6 \times 10^{-6}$ & $4 \times 10^{-4}$ & 0.999 & $4 \times 10^{-5}$ & $-6 \times 10^{-4}$ & 0.992 & -3.4 & 0.52 & 0.999 & 0.141 \\
\hline D & $-3 \times 10^{-6}$ & $4 \times 10^{-4}$ & 0.999 & $-1 \times 10^{-6}$ & $-4 \times 10^{-4}$ & 0.992 & -3.4 & 0.51 & 0.999 & 0.213 \\
\hline AuNPs & $1 \times 10^{-6}$ & $4 \times 10^{-4}$ & 0.999 & $-7 \times 10^{-6}$ & $-3 \times 10^{-4}$ & 0.999 & -3.4 & 0.49 & 0.999 & 0.140 \\
\hline
\end{tabular}

(A): No pre-treatment; (B): pre-treatment at every run; (C): pre-treatment and second electrochemical treatment before every run; (D): pre-treatment every run but second electrochemical treatment only in the initial run. Pre-treatment: 30 fast scans from 1.4 to $-0.9 \mathrm{~V}$ at $1.0 \mathrm{~V} / \mathrm{s}$ and 2 slow scans from 1.3 to $0.9 \mathrm{~V}$ at $0.1 \mathrm{~V} / \mathrm{s}$; second electrochemical treatment: $-1.0 \mathrm{~V}$ during $30 \mathrm{~s}$. 
Table 3

Summary of parameters obtained from mechanism and capacitance studies using electrode modifications E5-E8 and E13-E16.

\begin{tabular}{|c|c|c|c|c|c|c|c|c|}
\hline Electrode & $\begin{array}{c}C_{o b s} \\
@ 100 \mathrm{mV} / \mathrm{s} \\
{\left[\mathrm{mF} / \mathrm{cm}^{2}\right]}\end{array}$ & $\begin{array}{c}\text { Reprodu- } \\
\text { cibility } \\
(\%)\end{array}$ & $\begin{array}{c}C_{D L} \\
{\left[\mathrm{mF} / \mathrm{cm}^{2}\right]}\end{array}$ & $\begin{array}{c}\text { Reprodu- } \\
\text { cibility } \\
(\%)\end{array}$ & $\begin{array}{l}\text { Area } \\
\left(\mathrm{cm}^{2}\right)\end{array}$ & DC? & $\begin{array}{l}I_{a} / I_{c} \\
\text { ratio }\end{array}$ & $\begin{array}{c}E_{a}-E_{c} \\
\text { values }\end{array}$ \\
\hline E5 & 0.025 & 4 & 0.025 & 4 & 0.093 & Yes & $\sim 1$ & 0.128 \\
\hline E6 & 9.02 & 9 & 6.50 & 9 & 0.085 & Yes & $\sim 1$ & 0.144 \\
\hline E7 & 0.36 & 2 & 7.05 & 16 & 0.084 & Yes & $\sim 1$ & 0.130 \\
\hline E8 & 0.21 & 5 & 0.20 & 5 & 0.017 & Yes & $\sim 1$ & 0.28 \\
\hline E13 & 50 & 1 & 52 & 1 & 0.063 & Yes & $\sim 1$ & 0.08 \\
\hline E14 & 43 & 4 & 42 & 2 & 0.022 & Yes & 0.30 & 0.09 \\
\hline E15 & 17 & 5 & 16 & 4 & 0.062 & Yes & $\sim 1$ & 0.10 \\
\hline E16 & 30 & 7 & 27 & 2 & 0.106 & Yes & $\sim 1$ & 0.07 \\
\hline
\end{tabular}

$C_{o b s}$ : observed capacity; $C_{D L}$ : double layer capacity; DC: diffusion-controlled mechanism. 
Table 4

Analytical parameters obtained with CV measurements in Cys solutions of increasing concentrations using different electrodes. The values are the average of three different calibration curves. Working ranges are expressed from the limit of quantitation (LOQ) to the most concentrated solution keeping a linear behaviour.

\begin{tabular}{|l|c|c|c|c|c|c|}
\hline \multicolumn{1}{|c|}{ Electrode } & $\begin{array}{c}\text { Slope } \\
\left(\mathrm{A} \cdot \mu \mathrm{mol}^{-1} \cdot \mathrm{L}\right)\end{array}$ & $\begin{array}{c}\text { Intercept. } \\
(\mathrm{A})\end{array}$ & $\mathbf{R}^{2}$ & $\begin{array}{c}\text { LOD } \\
\left(\mu \mathrm{mol} \cdot \mathrm{L}^{-1}\right)\end{array}$ & $\begin{array}{c}\text { \%CV } \\
\text { slope }\end{array}$ & $\begin{array}{c}\text { Working } \\
\text { range } \\
\left(\mu \mathrm{mol} \cdot \mathrm{L}^{-1}\right)\end{array}$ \\
\hline Pre-treated SPAuE & $1.3 \times 10^{-7}$ & $4.5 \times 10^{-5}$ & 0.989 & 30 & 4 & $100-600$ \\
\hline Pre-treated SPAuE with AuNPs & $1.2 \times 10^{-7}$ & $5.1 \times 10^{-5}$ & 0.994 & 25 & 19 & $83-600$ \\
\hline $\begin{array}{l}\text { Pre-treated SPAuE with } \\
\text { MWCNTs and AuNPs }\end{array}$ & $1.1 \times 10^{-7}$ & $6.0 \times 10^{-5}$ & 0.995 & 24 & 28 & $81-600$ \\
\hline $\begin{array}{l}\text { Pre-treated SPAuE with } \\
\text { MWCNTs and AuNPs in Nafion }{ }^{\circledR}\end{array}$ & $8.4 \times 10^{-8}$ & $1.1 \times 10^{-5}$ & 0.983 & 84 & 41 & $280-600$ \\
\hline
\end{tabular}


Table 5. Analytical parameters obtained in the application of pre-treated gold screen-printed electrodes with gold nanoparticles as amperometric detectors in the HPLC-EC analysis of some aminothiols. The results are compared with these of other HPLC methods found in the literature.

\begin{tabular}{|c|c|c|c|c|}
\hline & Cys & Met & GSH & hCys \\
\hline $\mathrm{R}^{2}$ & 0.9951 & 0.9957 & 0.9766 & 0.9982 \\
\hline Slope $\left(A \cdot s \cdot \mu \mathrm{mol}^{-1} \cdot \mathrm{L}\right)$ & $2.42 \times 10^{-7}$ & $3.83 \times 10^{-7}$ & $5.08 \times 10^{-7}$ & $4.57 \times 10^{-7}$ \\
\hline Intercept $(A \cdot s)$ & $5.71 \times 10^{-6}$ & $1.81 \times 10^{-5}$ & $9.71 \times 10^{-6}$ & $1.38 \times 10^{-5}$ \\
\hline LOD $\left(\mu \mathrm{mol} \mathrm{L}^{-1}\right)$ this work & 3.1 & 1.0 & 0.1 & 0.6 \\
\hline LOD $\left(\mu \mathrm{mol} \mathrm{L}^{-1}\right)$ AD with Au-SPE [16] & 12 & 1 & 0.2 & 1 \\
\hline LOD $\left(\mu \mathrm{g} \mathrm{L}^{-1}\right)$ AD with GCE [18] & 0.6 & 1 & 9 & 0.4 \\
\hline LOD $\left(\mu \mathrm{mol} \mathrm{L}^{-1}\right)$ AD with Ag disk [17] & 0.2 & - & 0.2 & 0.3 \\
\hline $\begin{array}{l}\text { LOD }\left(\mu \mathrm{mol} \mathrm{L}^{-1}\right) \text { AD with carbon SPE modified } \\
\text { with graphene [46] }\end{array}$ & - & - & 0.4 & - \\
\hline LOD $\left(\mu \mathrm{mol} \mathrm{L}{ }^{-1}\right)$ UVD with derivatisation [11] & 0.04 & - & 0.06 & 0.08 \\
\hline LOD $\left(\mu \mathrm{mol} \mathrm{L}^{-1}\right)$ FD with derivatisation [12] & 0.09 & - & 0.03 & 0.05 \\
\hline LOQ $\left(\mu \mathrm{mol} \mathrm{L}^{-1}\right)$ this work & 10.3 & 3.3 & 0.3 & 2.2 \\
\hline LOQ $\left(\mu \mathrm{mol} \mathrm{L}^{-1}\right)$ AD with Au-SPE [16] & 40 & 2 & 0.5 & 2 \\
\hline LOQ $\left(\mu \mathrm{gL}^{-1}\right)$ AD with GCE [18] & 1 & 3.5 & 30 & 0.8 \\
\hline LOQ $\left(\mu \mathrm{mol} \mathrm{L}^{-1}\right)$ AD with Ag disk [17] & 0.3 & - & 0.3 & 0.3 \\
\hline $\begin{array}{l}\text { LOQ }\left(\mu \mathrm{mol} \mathrm{L}^{-1}\right) \text { AD with carbon SPE modified } \\
\text { with graphene }[46]\end{array}$ & - & - & 1.2 & - \\
\hline LOQ $\left(\mu \mathrm{mol} \mathrm{L}{ }^{-1}\right)$ UVD with derivatisation [11] & 0.12 & - & 0.15 & 0.15 \\
\hline LOQ $\left(\mu \mathrm{mol} \mathrm{L}^{-1}\right)$ FD with derivatisation [12] & 15 & - & 0.5 & 2 \\
\hline Working range $\left(\mu \mathrm{mol} \mathrm{L}{ }^{-1}\right)$ this work & $10-80$ & $3.3-30$ & $0.3-10$ & $2.2-30$ \\
\hline Working range $\left(\mu \mathrm{mol} \mathrm{L}^{-1}\right)$ AD with Au-SPE [16] & $40-600$ & $2-30$ & $0.5-10$ & $2-30$ \\
\hline Working range $\left(\mu \mathrm{g} \mathrm{L}^{-1}\right)$ AD with GCE [18] & $50-1000$ & $100-4000$ & $100-4000$ & $100-2000$ \\
\hline Working range $\left(\mu \mathrm{mol} \mathrm{L}^{-1}\right) \mathrm{AD}$ with $\mathrm{Ag}$ disk [17] & $0.2-20$ & - & $0.2-20$ & $0.2-20$ \\
\hline $\begin{array}{l}\text { Working range }\left(\mu \mathrm{mol}^{-1}\right) \mathrm{AD} \text { with carbon SPE } \\
\text { modified with graphene }[46]\end{array}$ & - & - & $1-1000$ & - \\
\hline $\begin{array}{l}\text { Working range }\left(\mu \mathrm{mol} \mathrm{L}^{-1}\right) \text { UVD with } \\
\text { derivatisation }[11]\end{array}$ & $0.15-500$ & - & $0.15-500$ & $0.15-500$ \\
\hline $\begin{array}{l}\text { Working range }\left(\mu \mathrm{mol} \mathrm{L}^{-1}\right) \mathrm{FD} \text { with } \\
\text { derivatisation }[12]\end{array}$ & $15-500$ & - & $0.5-7.5$ & $2-50$ \\
\hline
\end{tabular}

Cys: cysteine; Met: methionine; GSH: glutathione; hCys: homocysteine; SPE: screen-printed electrodes; AD: amperometric detection; UVD: UV detection; FD: fluorescence detection; GCE: glassy carbon electrode; LOD: limit of detection; LOQ: limit of quantification. 
Table 6. Results of the determination of cysteine and methionine in dietary supplements by the proposed LC-EC method.

\begin{tabular}{|l|c|c|}
\hline & Cysteine & Methionine \\
\hline Mean value determined $\left(\mu \mathrm{mol} \cdot \mathrm{L}^{-1}\right)$ & 38.9 & 9.9 \\
\hline Standard deviation $\left(\mu \mathrm{mol} \cdot \mathrm{L}^{-1}\right)$ & 1.2 & 0.6 \\
\hline Coefficient of Variation $(\%)$ & 3.1 & 6.1 \\
\hline $\begin{array}{l}\text { Concentration according to manufacturer } \\
\left(\mu \mathrm{mol} \cdot \mathrm{L}^{-1}\right)\end{array}$ & 40.0 & 10.0 \\
\hline Relative error $(\%)$ & 2.8 & 1.0 \\
\hline
\end{tabular}




\section{Supplementary Material}

\section{Screen-printed electrodes modified with green-synthesized gold nanoparticles for the electrochemical determination of aminothiols}

Valeree Ross R. Bernardo-Boongaling ${ }^{1,3}$, Núria Serrano ${ }^{1}$, Juan José García-Guzmán ${ }^{3}$, José María Palacios-Santander ${ }^{3}$, José Manuel Díaz-Cruz ${ }^{1,2 *}$.

1 Department of Chemical Engineering and Analytical Chemistry, University of Barcelona, Martí i Franquès 1-11, 08028-Barcelona, Spain.

2 Institut de Recerca de l'Aigua (IdRA), University of Barcelona.

3 Institute of Research on Electron Microscopy and Materials (IMEYMAT), Department of Analytical Chemistry, Faculty of Sciences, Campus de Excelencia Internacional del Mar (CEIMAR), University of Cadiz, Campus Universitario de Puerto Real, Polígono del Río San Pedro S/N, 11510, Puerto Real, Cádiz, Spain

*Corresponding author. Phone: (34) 9340217 96, e-mail: josemanuel.diaz@ub.edu

Table S1

Results of the mechanism study for bare SPAuE devices submitted to different conditions (A, B, $C$ and $D$ ) and modified with gold nanoparticles after a type $B$ conditioning (AuNPs). Measurements were made in a $5.0 \mathrm{mmol} \mathrm{L}^{-1}$ of $\mathrm{K}_{4}\left[\mathrm{Fe}(\mathrm{CN})_{6}\right]$ solution.

\begin{tabular}{|l|c|c|c|c|c|}
\hline Treatment & $\mathrm{A}$ & $\mathrm{B}$ & $\mathrm{C}$ & $\mathrm{D}$ & AuNPs \\
\hline Kinetics & $\begin{array}{c}\text { Diffusion- } \\
\text { controlled }\end{array}$ & $\begin{array}{c}\text { Diffusion- } \\
\text { controlled }\end{array}$ & $\begin{array}{c}\text { Diffusion- } \\
\text { controlled }\end{array}$ & varies & $\begin{array}{c}\text { Diffusion- } \\
\text { controlled }\end{array}$ \\
\hline$I_{a} / I_{c}$ ratio & $\sim 1$ & $\sim 1$ & $\sim 1$ & $\sim 1$ & $\sim 1$ \\
\hline$E_{a}-E_{c}(\mathrm{~V})$ & $0.073-0.083$ & $0.058-0.108$ & $0.059-0.118$ & $0.059-0.098$ & $0.078-0.093$ \\
\hline
\end{tabular}

(A): No pre-treatment; (B): pre-treatment at every run; (C): pre-treatment and second electrochemical treatment before every run; (D): pre-treatment every run but second electrochemical treatment only in the initial run. Pre-treatment: 30 fast scans from 1.4 to $-0.9 \mathrm{~V}$ at $1.0 \mathrm{~V} / \mathrm{s}$ and 2 slow scans from 1.3 to $0.9 \mathrm{~V}$ at $0.1 \mathrm{~V} / \mathrm{s}$; second electrochemical treatment: $-1.0 \mathrm{~V}$ during $30 \mathrm{~s}$. 


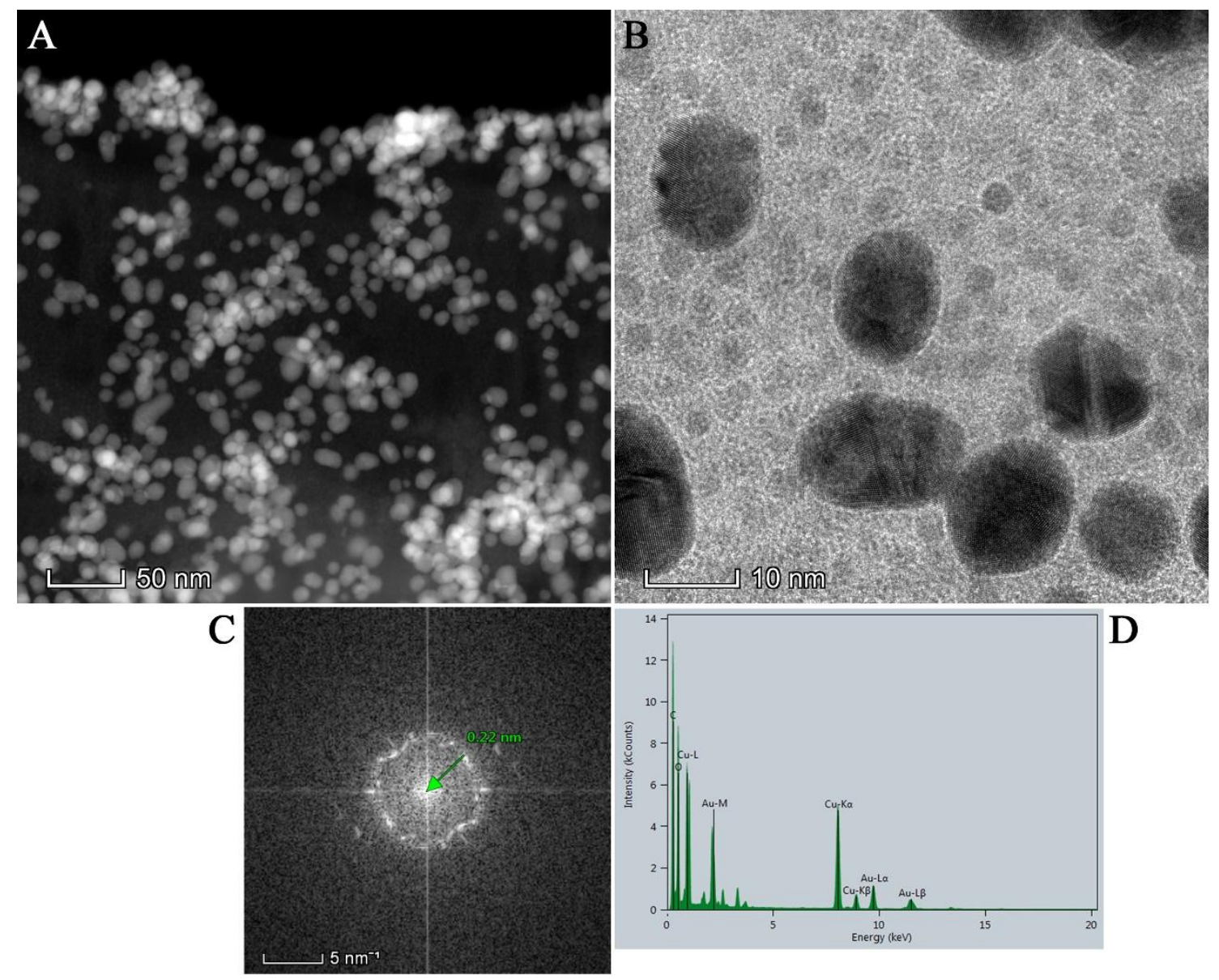

Figure S1: TEM micrographs of AuNPs, green synthesized by a high energy ultrasound probe, taken at $200 \mathrm{kV}$ using: A) the scanning/transmission (STEM) mode with a high-angle annular dark-field (HAADF) detector and B) the high resolution mode (HREM). C) Digital Diffraction Pattern (DDP) built from the HREM image and D) energy dispersive $X$-ray spectrum of the sample. 
Figure S2
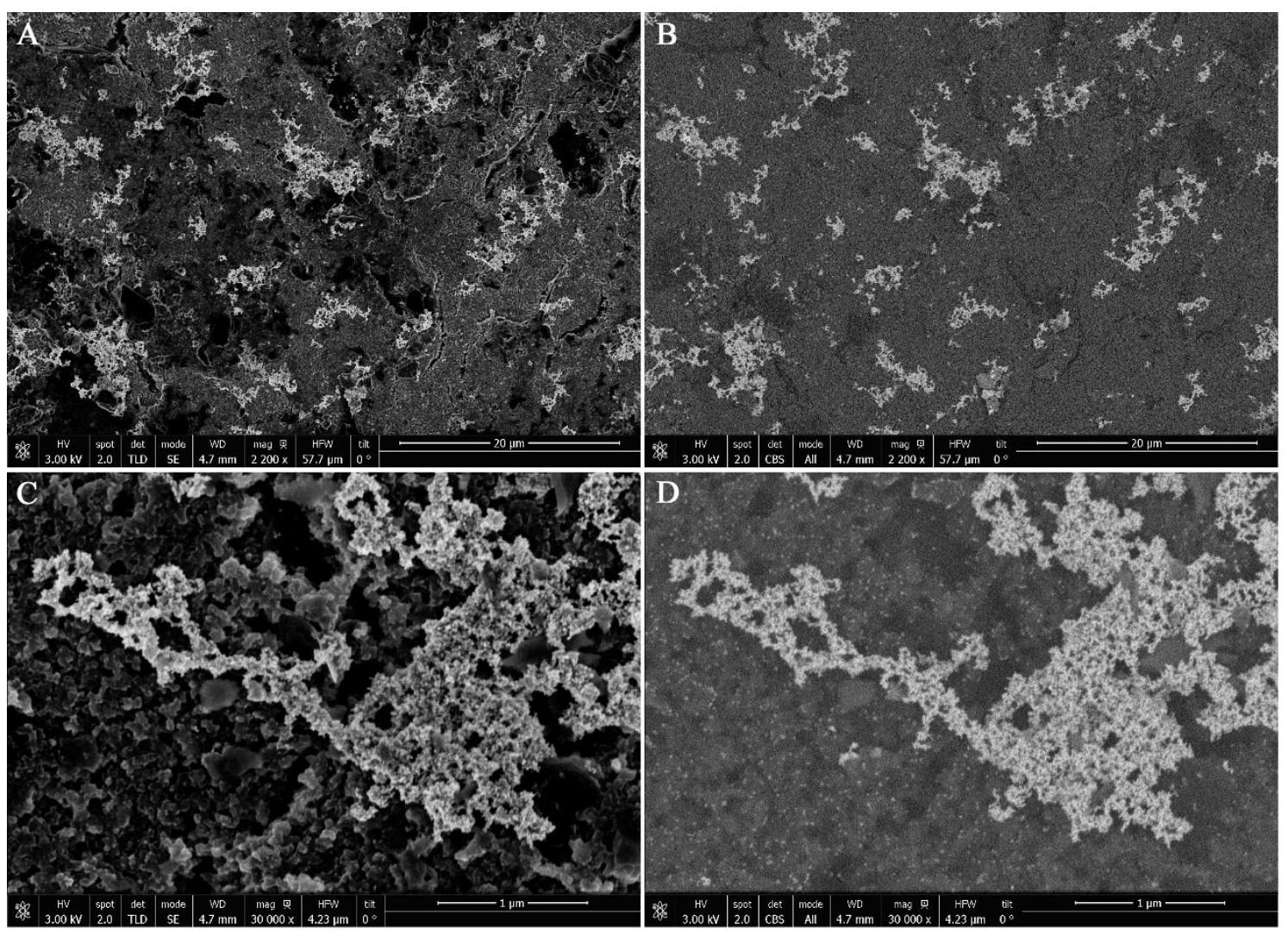

Figure S2: SEM micrographs of a screen-printed electrode with AuNPs deposited onto its surface: A) and B) generic overview of the AuNPs-modified electrode surface at lower magnification, and $C$ ) and $D$ ) detail of a bigger AuNPs agglomerate and AuNPs onto the surface at higher magnification (represented as tiny white dots in D). Micrographs on the left ( $A$ and $C$ ) and on the right ( $B$ and $D$ ) were taken with secondary and backscattered electrons detectors, respectively. 
Figure S3
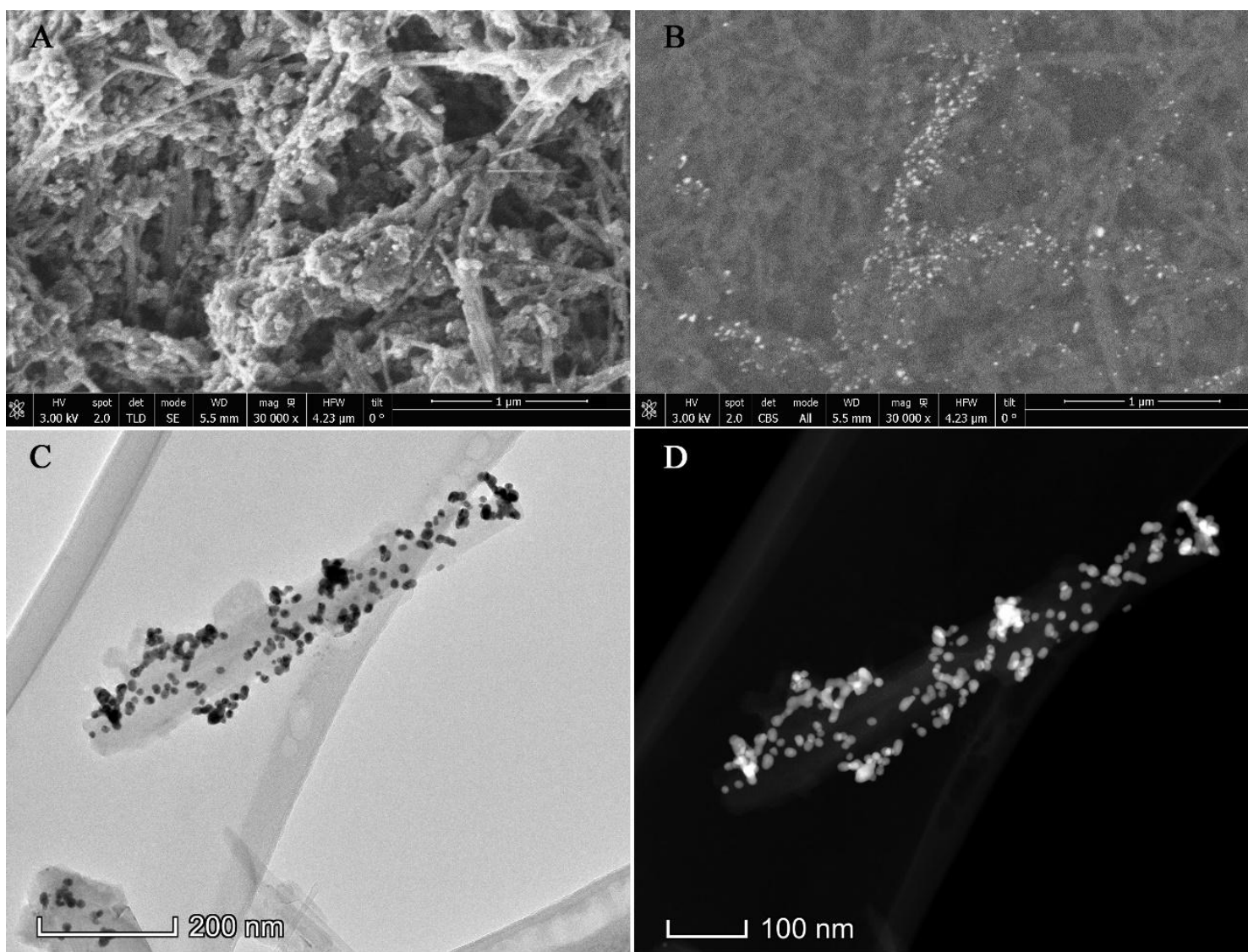

Figure S3: SEM and TEM micrographs of MWCNTs/AuNPs nanocomposite: A) and B) SEM images taken with the secondary electrons and backscattered electrons detectors, respectively; C) and D) TEM images ( $\times 46,000)$ obtained at $200 \mathrm{kV}$ with the HREM and HAADFSTEM modes, respectively. 
Figure S4

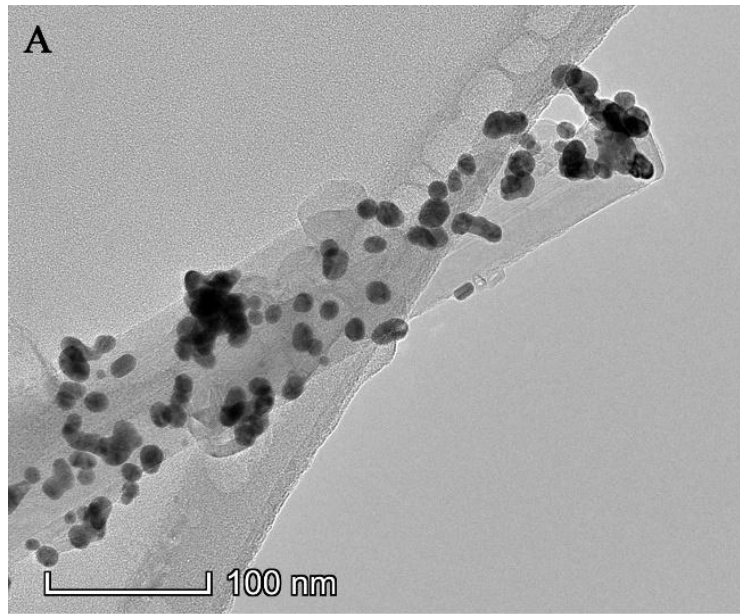

\section{B}

C
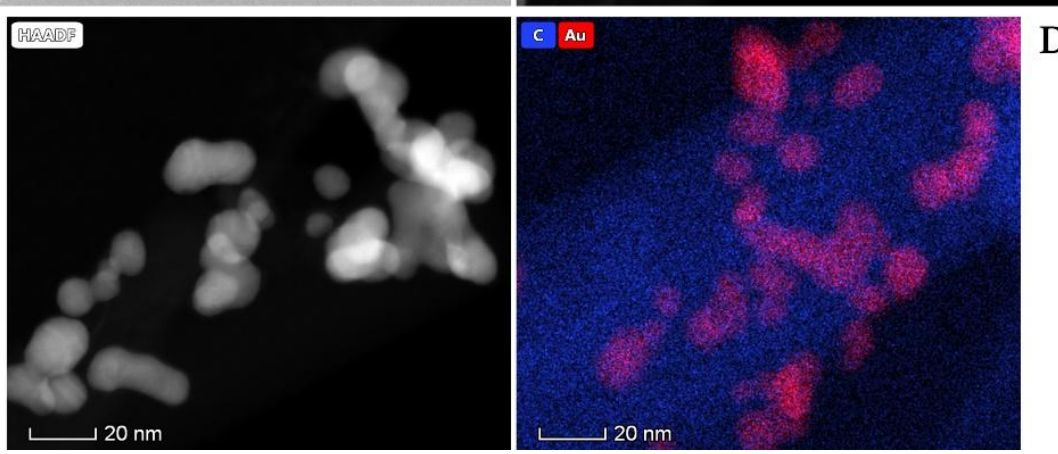

Figure S4: TEM micrographs of MWCNTs/AuNPs nanocomposite at higher magnification $(\times 95,000)$ : detail of MWCNTs with AuNPs on the surface obtained at $200 \mathrm{kV}$ with the A) HREM mode and B) HAADF-STEM modes; C) zoom of the MWCNT/AuNPs nanocomposite tip appearing in micrograph B, and D) compositional map of the MWCNT/AuNPs nanocomposite structure in micrograph $\mathrm{C}$ ): red color $=\mathrm{Au}$ atoms from AuNPs and blue color $=\mathrm{C}$ atoms from MWCNT and from the grid in the darker parts. 